OPEN ACCESS

Edited by:

Massimiliano Mazzone, KU Leuven, Belgium

Reviewed by:

Paola Italiani,

Italian National Research Council

(CNR), Italy

Stamatia Papoutsopoulou, University of Liverpool, United Kingdom

*Correspondence: Joel D. Schilling schillij@wustl.edu

Specialty section: This article was submitted to

Molecular Innate Immunity, a section of the journal

Frontiers in Immunology

Received: 18 October 2019 Accepted: 23 December 2019

Published: 22 January 2020

Citation:

Daemen S and Schilling JD (2020) The Interplay Between Tissue Niche and Macrophage Cellular Metabolism in Obesity. Front. Immunol. 10:3133.

doi: 10.3389/fimmu.2019.03133

\section{The Interplay Between Tissue Niche and Macrophage Cellular Metabolism in Obesity}

\author{
Sabine Daemen ${ }^{1}$ and Joel D. Schilling ${ }^{1,2 *}$ \\ ${ }^{1}$ Department of Medicine, Washington University School of Medicine, St. Louis, MO, United States, ${ }^{2}$ Department of \\ Pathology and Immunology, Washington University School of Medicine, St. Louis, MO, United States
}

Obesity is associated with the development of metabolic diseases such as type 2 diabetes and non-alcoholic fatty liver disease. The presence of chronic, low-grade inflammation appears to be an important mechanistic link between excess nutrients and clinical disease. The onset of these metabolic disorders coincides with changes in the number and phenotype of macrophages in peripheral organs, particularly in the liver and adipose tissue. Macrophage accumulation in these tissues has been implicated in tissue inflammation and fibrosis, contributing to metabolic disease progression. Recently, the concept has emerged that changes in macrophage metabolism affects their functional phenotype, possibly triggered by distinct environmental metabolic cues. This may be of particular importance in the setting of obesity, where both liver and adipose tissue are faced with a high metabolic burden. In the first part of this review we will discuss current knowledge regarding macrophage dynamics in both adipose tissue and liver in obesity. Then in the second part, we will highlight data linking macrophage metabolism to functional phenotype with an emphasis on macrophage activation in metabolic disease. The importance of understanding how tissue niche influences macrophage function in obesity will be highlighted. In addition, we will identify important knowledge gaps and outstanding questions that are relevant for future research in this area and will facilitate the identification of novel targets for therapeutic intervention in associated metabolic diseases.

Keywords: obesity, insulin resistance, non-alcoholic fatty liver disease, macrophages, metabolism, liver, adipose tissue

\section{INTRODUCTION}

Adipose tissue and liver contain tissue resident macrophages that are indispensable for tissue homeostasis. Tissue macrophages can either be derived from primitive hematopoiesis in the embryonic yolk-sac or from definitive hematopoiesis from the fetal liver or bone marrowderived monocytes (1). Fate-mapping studies have revealed that the majority of tissue-resident macrophages are initially derived from the embryonic yolk-sac and maintain via self-renewal; however, this varies amongst tissues (1). Although circulating monocytes contribute to the resident macrophage pool in some tissues, monocyte-derived macrophages (MdMs) predominantly enter tissues in states of tissue injury or inflammation. Cellular origin may be one factor that contributes 
to the functionality of tissue macrophages; however, these cells display a high degree of plasticity and can readily adapt their functional state in response to environmental cues. Indeed, the transcriptome of resident macrophages from different tissues is very distinct (2), despite similar cellular origins. Thus, tissue niche is arguably the most important driver of resident macrophage function. However, the cellular and molecular pathways that program the resident macrophage identity are just beginning to be understood $(3,4)$. Although tissue resident macrophages share common functions, including tissue remodeling and clearance of cellular debris, they can also exert specific tissue function. For example, alveolar macrophages regulate pulmonary surfactant homeostasis (5) and liver Kupffer cells (KCs) play an important role in iron metabolism (6). However, it is largely unclear if and how changes in the tissue microenvironment with obesity affect tissue macrophage function and what the consequences are for tissue homeostasis and pathology.

Traditionally, macrophage activation has been described by the two-dimensional M1 and M2 spectrum, i.e., classical or alternative activation, respectively. Recently, this paradigm has been replaced by the concept that there is a continuous spectrum of macrophage activation that can be shaped by tissue environment, cell programming, and activating stimuli. In large part, this notion has arisen from data using fate mapping and phenotyping techniques combined with systems biology (7). Therefore, identifying macrophage subsets in health and disease requires a combined approach based on surface marker expression, (single cell) RNA sequencing and functional/metabolic phenotyping. In the setting of obesity there are extensive shifts in macrophage number and activation state in the adipose tissue and liver and these changes contribute to metabolic disease progression. Macrophage lipotoxicity has been well-described and contributes to complications of obesity such as atherosclerosis, insulin resistance, and non-alcoholic fatty liver disease (NAFLD). Metabolic programming of macrophages themselves can also influence cell function and is particularly relevant to inflammation associated with nutrient excess. However, the interplay between macrophage cellular metabolism and tissue niche during the development of obesity and its complications is poorly understood. This review will address the current knowledge on altered macrophage dynamics in adipose tissue and liver in obesity. Furthermore, we will elaborate on the interplay between systemic metabolic perturbations and cellular metabolism in macrophages in the setting of excess lipids. The potential of targeting macrophage metabolic function to modulate obesity complications will also be discussed.

\footnotetext{
Abbreviations: ATM, adipose tissue macrophage; CLS, crown-like structures; DCs, dendritic cells; FAO, fatty acid oxidation; HFD, high fat diet; KCs, Kupffer cells; LAMs, Lipid-associated macrophages; MdMs, monocyte-derived macrophages; NAFLD, non-alcoholic fatty liver disease; NAMs, NASH-associated macrophages; NASH, non-alcoholic steatohepatitis; OXPHOS, oxidative phosphorylation; PPP, pentose phosphate pathway; scRNA-seq, single cell RNA sequencing; TCA cycle, tricarboxylic acid cycle.
}

\section{MACROPHAGE DYNAMICS IN OBESE ADIPOSE TISSUE}

\section{Accumulation of Adipose Tissue Macrophages in Obesity}

Lean adipose tissue contains resident macrophages that reside between adipocytes and alongside vascular structures. These resident adipose tissue macrophages (ATMs) have various roles in adipose tissue homeostasis including efferocytosis (i.e., removal of dead adipocytes), lipid buffering, and adipogenesis (Figure 1) (8). In addition, resident ATMs are important for the expansion and contraction of adipose tissue that occurs with changes in fat mass (9). Although the origin and maintenance of resident ATMs is less well-understood it was recently shown that resident ATMs in healthy murine adipose tissue are predominantly derived from embryonic yolk-sac precursors and can self-renew via proliferation $(10,11)$. However, bone marrowderived macrophages also contribute to the resident ATM pool $(10,12)$. Excess ATMs can be eliminated by type 1 innate lymphoid cells (13), thereby maintaining a homeostatic ATM number and potentially preventing unwanted inflammation.

In obesity, adipose tissue expands and there is a marked accumulation of macrophages $(14,15)$. While in lean adipose tissue ATMs represent about $5-10 \%$ of stromal cells, in obese adipose tissue this increases up to $40-50 \%$ in mice (14). In humans, a similar increase in adipose macrophage content has been demonstrated (16-18). The expansion of macrophages with obesity was initially thought to result from the recruitment of Ly6C ${ }^{\text {hi }}$ monocytes to adipose tissue (14). In line with this, higher levels of monocyte chemoattractants are present in obese adipose tissue, most notably monocyte chemoattractant protein1 (MCP-1, also known as CCL2) (19). In addition, labeling studies have shown that circulating monocytes can enter obese adipose tissue via mechanism that is largely dependent on CCR2, the receptor for CCL2 (20). However, subsequent data has also shown that in addition to recruitment, local proliferation of ATMs also contributes to the increase in macrophage numbers observed in obese adipose tissue $(21,22)$. Importantly, these models are not mutually exclusive and likely both contribute as recruited monocyte-derived cells can also proliferate. Other local mechanisms may also contribute to increased macrophage numbers, including increased tissue retention. This is possibly mediated by Netrin-1 (23), which has been implicated in the regulation of cellular migration of various cell types.

In addition to increases in number, the localization and organization of ATMs within the tissue changes with obesity. Whereas, in lean adipose tissue ATMs are interstitially spaced, in the obese setting ATMs form clusters. These sites of macrophage accumulation are known as crown-like structures (CLS), in which macrophages appear to surround apoptotic adipocytes $(24,25)$. Interestingly, local proliferation of ATMs occurs predominantly in CLS (21). The role of these macrophages will be discussed more in the next section.

\section{ATM Phenotype in Obesity}

Macrophage phenotype also changes in obese adipose tissue. Macrophages in murine lean adipose tissue have been 


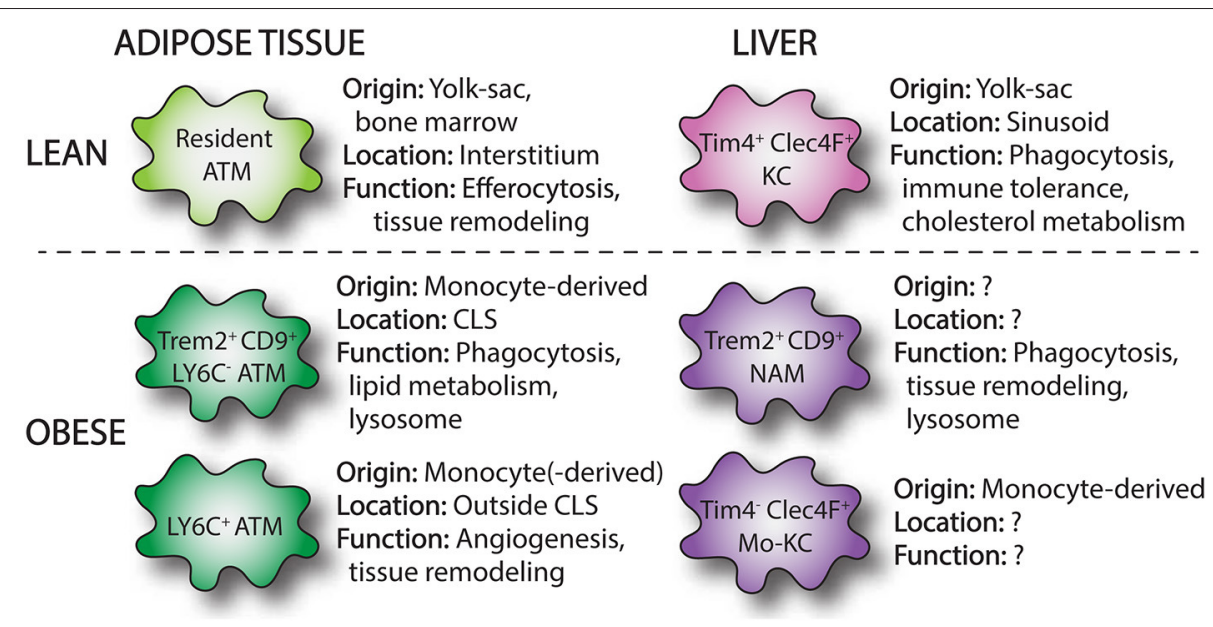

FIGURE 1 | Overview of macrophages subsets in lean and obese adipose tissue and liver. Single-cell RNA sequencing has identified macrophage subpopulations that accumulate in liver and adipose tissue in the setting of obesity. These obese adipose tissue macrophages (ATMs) and NASH-associated macrophages (NAMs) are derived from infiltrating monocytes and display distinct surface markers (Trem2, CD9) and functions compared to resident tissue macrophages. In the liver, loss of resident KCs in NASH induces the appearance of monocyte-derived KCs (mo-KCs), which likely fill the empty KC niche and may exert similar functions to resident KCs.

characterized as $\mathrm{F} 4 / 80^{+}, \mathrm{CD}_{11 \mathrm{~b}}+, \mathrm{CD} 206^{+}, \mathrm{CD} 01^{+}$cells. In obese adipose tissue, $\mathrm{CCR} 2^{+} / \mathrm{Ly} 6 \mathrm{C}^{\text {hi }}$ monocytes enter the tissue where they can differentiate to ATMs and/or proliferate (26). Early studies demonstrated that increased expression of CD11c is a common feature of ATMs present in obese adipose tissue, particularly in monocyte-derived cells $(27,28)$. Although CD11c can be help identify recruited ATMs, this receptor is also expressed by adipose tissue dendritic cells (DCs). Thus, additional markers, such as the macrophage marker CD64, are necessary to distinguish CD11c ${ }^{+}$ATMs from DCs.

As mentioned above, the activation of state of macrophages in obesity has often been described based upon the two-dimensional M1 and M2 activation states (29). In this respect, a switch from an anti-inflammatory M2 phenotype to proinflammatory M1 phenotype was thought to occur in obese adipose tissue (30). In support of this model, lean adipose tissue macrophages have an "M2-like" phenotype characterized by gene expression of anti-inflammatory genes, such as $\mathrm{Ym} 1$, arginase 1, and IL$10(30,31)$, whereas $\mathrm{F} 4 / 80^{+}, \mathrm{CD}_{11 \mathrm{c}^{+}}$ATMs express genes ascribed to classically activated M1 macrophages, including iNOS and TNF $\alpha$ (31). However, this concept was initially challenged by data obtained from flow-sorted macrophages revealing that upregulation of lysosomal genes was the strongest transcriptional signal in ATMs from obese mice. Thus providing evidence that tissue remodeling and phagocytosis may be more relevant functions of ATMs than the release of proinflammatory cytokines (32). This concept has subsequently been confirmed by two recent studies from independent labs that used single cell RNA sequencing (scRNA-seq) to demonstrate substantial differences between murine and human ATMs in obesity compared to M1 or M2 phenotypes $(33,34)$. In one of these studies, the tetraspanin CD9 together with Ly6C were identified as markers to define three distinct subsets of ATMs; $\mathrm{Ly}_{6 \mathrm{C}}^{+}$, Ly6C ${ }^{-} \mathrm{CD}^{-}$, and $\mathrm{Ly}^{-} \mathrm{C}^{-} \mathrm{CD} 9^{+}$(33). The
Ly6C ${ }^{+}$population of cells likely represents monocytes, whereas the $\mathrm{Ly} 6 \mathrm{C}^{-}$populations are true ATMs. Interestingly, CD11c expression was variable within the three subpopulations but was highest in the $\mathrm{CD}^{+}$macrophages. Importantly, these three ATM/monocyte subsets displayed distinct tissue localization and gene expression patterns. Ly6C ${ }^{+}$monocytes had a uniform tissue distribution outside of CLS and were adipogenic, whereas CD9 ${ }^{+}$ATMs specifically resided within CLS, had high amounts of intracellular lipid and expressed proinflammatory genes (Figure 1). When $\mathrm{CD}^{+}$ATMs were transplanted into lean mice they induced expression of inflammatory genes in the adipose tissue. Interestingly, lipid-laden $\mathrm{CD}^{+}$ATMs were also detected in human obese adipose tissue and localized to CLS (33). Subsequently, Jaitin et al. also used a scRNAseq approach and confirmed that $\mathrm{CD}^{+}$ATMs accumulate in obese adipose tissue and localize to adipose tissue CLS (34). In this study, these macrophages were referred to as LipidAssociated Macrophages (LAMs) due to their location around lipid droplets and their high expression of genes involved in phagocytosis and lipid metabolism (Figure 1). In addition, LAMs express high levels of the lipid receptor Trem2 and knock out of this receptor in bone marrow cells worsened the metabolic consequences of obesity. This observation suggests that although these ATMs have some pro-inflammatory characteristics they actually play a beneficial role in obese adipose tissue. This duality of macrophage function in obesity is also supported by data from mice lacking the enzyme NADPH oxidase 2 (NOX2) in macrophages. In these mice, loss of NOX2 diminishes inflammatory cytokine production, but also impairs the clearance of dead adipocytes upon high-fat diet (HFD) feeding. As a result, myeloid-NOX2 KO mice have decreased adipose tissue inflammation and improved glucose tolerance early in disease, but develop profound insulin resistance and steatohepatitis upon prolonged HFD. Thus, although ATMs in obesity have been 
viewed as pathologic, mainly due to their pro-inflammatory potential, they also perform beneficial functions such as the clearance of dead adipocytes and buffering of excess fatty acids (35). This concept is important to consider when designing and interpreting experimental results as the timepoint of analysis can yield divergent results. Together this data supports a model whereby $\mathrm{CD}^{+} / \mathrm{Trem}^{+}$ATMs can play either proinflammatory or reparative roles in adipose tissue based on disease severity.

Human ATMs are characteristically $\mathrm{CD} 14^{+} / \mathrm{CD} 16^{-}$and express markers CD68, CD163, CD204, and CD206 in lean adipose tissue. It has been recognized that in humans, ATMs barely express markers used for M1 and M2 classification, such as iNOS and arginase-1 (36). Rather human ATMs in obese adipose tissue express a mixed phenotype illustrated by expression of both CD11c, an M1 marker, and CD206 and CD163, markers of $\mathrm{M} 2$ activation (37-39). CD11c ${ }^{+}, \mathrm{CD} 206^{+}$macrophages have been shown to correlate with insulin resistance (38), whereas the number of $\mathrm{CD}_{11 \mathrm{c}^{+}}, \mathrm{CD} 163^{+}$cells associated with BMI (39). Furthermore, CD163 was found to be the only marker to track with HOMA-IR (40). Analogous to the murine system, human ATMs appear to simultaneously have the potential to release pro-inflammatory cytokines including TNF $\alpha$, IL-6, IL-1, and MCP-1 while also expressing factors associated with tissue remodeling and homeostasis such as IL-10 and TGF $\beta(37,41)$. As mentioned above, CD9 ${ }^{+}$ATMs resembling LAMs have been described in humans; however, further work will be necessary to assess whether these immune cells play similar functions in both species.

In summary, obesity drives ATM accumulation and shifts in gene expression that are not well-captured by the classical M1/M2 model. More in depth analysis with detailed phenotyping of obese ATMs in both mice and humans has revealed an alternative model of ATM activation in adipose tissue characterized by an upregulation of cell adhesion, lipid metabolism, and lysosomal genes. The cues that lead to ATM activation appear to be related to metabolic factors such as free fatty acids, lipoproteins, glucose and insulin; a state referred to as metabolically activated macrophages $(32,35,42)$. Further understanding of the metabolic signaling events that shape adipose tissue macrophage phenotype including their adaptive and detrimental roles will be critical to unlock the therapeutic potential of immune modulation during obesity.

\section{MACROPHAGE DYNAMICS IN LIVER}

\section{Resident and Infiltrating Macrophages}

In contrast to the adipose tissue, the liver contains a robust population of resident macrophages known as Kupffer cells (KCs). KCs represent $35 \%$ of all liver non-parenchymal cells and are the largest tissue population of resident macrophages in the body. They are largely derived from erythromyeloid progenitors of the embryonic yolk sac and maintained by selfrenewal $(43,44)$. These resident macrophages appear critical for liver (immune) homeostasis (Figure 1). KCs are intravascular and line the endothelium of the liver sinusoids where they represent a first line of defense to gut-derived pathogens, microbes, and toxins. Together with other immune cells, KCs are important for mediating immune tolerance, at least in part by the expansion of regulatory T-cells (45). In addition, their long cytoplasmic extensions can extend into the extravascular space and allow for contact with liver parenchymal cells. Beyond immune homeostasis, KCs can regulate the metabolism of iron, bilirubin, as well as cholesterol (46). In mice, KCs are traditionally characterized as $\mathrm{F} 4 / 80^{\mathrm{hi}}, \mathrm{CD} 11 \mathrm{~b}^{\mathrm{int}}, \mathrm{CD} 8^{+}$cells. Recently, additional surface markers have been described that specifically identify KCs from other myeloid cells in the liver including T-cell immunoglobulin, mucin domain containing 4 (Tim4), and C-type lectin domain family 4 member F (Clec4F) (Figure 1) (47, 48). In addition, KCs lack expression of CCR2 and $\mathrm{Cx} 3$-chemokine receptor 1 (Cx3cr1) (12). MdMs are derived from bone-marrow hematopoietic stem cells and are present in small numbers in the liver under physiologic conditions. Murine monocytes infiltrating the liver are characterized as $\mathrm{CD}_{11 \mathrm{~b}}{ }^{+}, \mathrm{Cx} 3 \mathrm{Cr}^{+}, \mathrm{Ly}_{6 \mathrm{c}^{+}}$. In addition, CCR2 is expressed at high level and regulates monocyte influx into the liver. Upon entry into the liver, monocytes downregulate Ly6C and undergo a maturation process to $\mathrm{MdMs}$, which is poorly understood but appears to be dependent upon the local tissue environment. Monocytes become a significant contributor to the liver macrophage pool in circumstances of $\mathrm{KC}$ depletion or tissue injury/inflammation (48). Upon experimental depletion of KCs, it has been demonstrated that monocytes can give rise to bona fide $\mathrm{KCs}$ which repopulate the empty $\mathrm{KC}$ niche $(47,48)$. Although these monocyte-derived KCs resemble their yolk sac brethren, there are some transcriptional programs that remain distinct (42). However, it is yet clear to what extent this differentiation process occurs with liver pathology such as NAFLD.

Human KCs as well as MdMs are less well-characterized and distinctive markers are lacking. KCs have often been characterized by their expression of CD68 and CD14. However, MdMs also express these markers. A recent study using RNA sequencing revealed two distinct populations of $\mathrm{CD}^{+} 8^{+}$liver macrophages in the healthy human liver, with one population having an inflammatory gene expression pattern and the second population was characterized by an immunotolerance phenotype (49). These populations could be distinguished by unique expression of MARCO in the immunotolerance population. More recently scRNA-seq data from humans with cirrhosis suggests that KCs also express CD163 and Tim4 in addition to MARCO (50), a phenotype that is analogous to KCs in mice (47). However, the ontogeny of these liver macrophages and whether these macrophage subtypes include MdMs in addition to true KCs is not known. The markers for monocytes and MdMs in the human liver are less well-understood, but include CCR2, Cx3cr1, SA100A2, and CD14 (50). Ongoing investigation will continue to establish the relationship between murine liver macrophage populations and their human counterparts.

\section{Macrophages in Obesity and NAFLD}

Obesity manifests in the liver as non-alcoholic fatty liver disease (NAFLD). Although it was initially tempting to speculate that similar inflammatory responses might 
occur in both adipose tissue and liver with obesity, it is now apparent that these organs respond in very different ways to lipid stress. NAFLD is characterized by excessive hepatic lipid accumulation, which can result in hepatocyte injury and cell death. This can trigger an inflammatory response and progression to non-alcoholic steatohepatitis (NASH), advanced fibrosis, cirrhosis, and hepatocellular carcinoma (51). Macrophages are important mediators of the inflammatory response which underlies the progression of NAFLD to NASH. Dietary models of NAFLD in mice have demonstrated an increase in liver macrophages number during NAFLD development $(52,53)$, but this finding has not been consistent with many studies also reporting no increase in total macrophage count $(54,55)$. Regardless, an important role of liver macrophages in NASH development has been demonstrated by depletion of liver macrophages by clodronate or gadolinium chloride, which have been shown to attenuate hepatic steatosis and decrease inflammation $(53,56-58)$.

Numerous studies have suggested macrophages take on a proinflammatory phenotype in NAFLD, which is likely mediated by a variety of environmental signals. To this end it has been shown that excessive accumulation of toxic lipids by KCs in the steatotic liver led to dysregulated lipid handling and increased pro-inflammatory gene expression (59). Inflammatory activation of KCs can also be regulated by danger signals released from hepatocyte damage and death (46) and by increased bacterial products from the gut due to gut dysbiosis in obesity (60). In addition to resident $\mathrm{KCs}, \mathrm{CCR} 2^{+}, \mathrm{Cx} 3 \mathrm{cr}^{+}{ }^{+}, \mathrm{Ly}_{6 \mathrm{C}} \mathrm{Ci}^{\text {monocytes }}$ infiltrate the liver in experimental models of NASH and appear to give rise to "pro-inflammatory" macrophages (61). However, in many of these earlier studies KCs could not be distinguished from MdMs and therefore the specific roles of resident vs. recruited cells in liver inflammation is not well-defined.

CCR2 is a critical chemokine receptor for monocyte recruitment into tissue. While genetic or pharmacologic disruption of CCR2 appears to attenuate liver inflammation with obesity this has not been consistent across CCR2 loss of function models (62-64). As such, the role of resident vs. recruited cells in NASH progression has remained controversial. In addition to CCR2, the chemokine receptor CXCR3 has also been described to play a role in monocyte recruitment (65). CCL2 can be secreted by KCs, hepatocytes, stellate cells and sinusoidal endothelial cells to facilitate monocyte recruitment. KC depletion by clodronate suppresses the infiltration of monocytes into the liver, potentially due to decreased CCL2 release $(53,66)$; however, these studies are challenging to interpret as clodrolip also depletes monocytes directly. Liver sinusoidal endothelial cells also upregulate VCAM-1 in response to inflammation thereby facilitating adhesion of monocytes (67). Related to this, it has been reported that under lipotoxic stress hepatocytes release extracellular vesicles which are enriched with the integrin ITG $\beta_{1}$, a VCAM-1 ligand, which subsequently enhances monocyte adhesion to sinusoidal endothelial cells (68).

Monocyte infiltration is also an important feature of human NASH and is especially seen in patients with more severe disease states and advanced liver fibrosis $(69,70)$. Similar to what has been described in the adipose tissue, a key feature of both human and mice NASH is the presence of macrophage aggregates termed crown-like structures $(64,71)$. These macrophage aggregates appear to surround dead or dying hepatocytes with large lipid droplets and colocalize with areas of fibrosis and activated stellate cells (64). The number of CLS positively correlates with the extent of fibrosis, suggesting that these structures may serve as hot spots for stellate cell activation (71). Thus, it is likely that the interplay between liver macrophages and hepatic stellate cells activation contributes to the tissue fibrosis observed in NASH (72-74). However, it remains unclear what drives the formation of hepatic CLS, what cells contribute to these aggregates, and what functions these cells have in the progression of NASH and fibrosis development.

On the other hand, macrophages with an anti-inflammatory and restorative phenotype have been demonstrated to reduce NASH severity (75-77). KCs themselves can promote antiinflammatory responses including the secretion of IL-10, which can trigger apoptosis of inflammatory macrophages (75). Furthermore, infiltrating macrophages can adopt a restorative phenotype characterized by high $\mathrm{Cx} 3 \mathrm{cr} 1$ expression and expression of genes involved in matrix remodeling (74). In human NASH increased expression of markers associated with alternative activation of macrophages has also been detected (78). Thus, similarly as described for adipose tissue, it is likely that liver macrophages perform beneficial roles in an attempt to restore liver injury.

Although it is clear that both resident and monocyte-derived macrophages play an important role in the progression of simple steatosis to NASH, the dynamics and function of these distinct macrophage subsets in the pathogenesis of NASH is unclear. The heterogeneity amongst MdMs themselves also appears to be more complex than appreciated. In part this may be related to the use of suboptimal macrophage markers and the assumption that all resident macrophages are $\mathrm{F} 480^{\mathrm{hi}}$, CD $11 b^{\text {int }}$ while $\mathrm{MdMs}$ are $\mathrm{CD} 11 \mathrm{~b}^{\text {hi }}, \mathrm{F} 4 / 80^{\text {int }}$. In support of this concept, it was recently reported that resident $\mathrm{KCs}$ are depleted upon MCD-diet feeding even though F4/80hi cells remain constant due to influx of MdMs. Moreover, this study also revealed that one potential fate of monocyte-derived cells is to become monocyte-derived KCs (mo-KCs, Figure 1) (79). More recently, scRNA-seq analysis in HFD fed mice (amylin diet) uncovered a unique subset of Trem $2^{+}, \mathrm{CD}^{+}$, $\mathrm{Gpnmb}^{+}$macrophages in the liver referred to as NASHassociated macrophages (NAMs, Figure 1). Gene expression analysis points toward a potential role of NAMs in the clearance of apoptotic and lipid debris as well as tissue remodeling (80). Interestingly, NAMs display some overlapping surface markers and transcriptional programs with LAMs. Whether these cells function in a similar way as LAMs in tissue remodeling is not known.

Future studies will be required to dissect the dynamic shifts that occur in macrophage subsets during NASH pathogenesis. In addition, the specific cues that induce macrophage polarization in NAFLD are not completely understood and the interplay between metabolic cues and macrophage function may be crucial for NASH progression. 


\section{The Role of Macrophages in the Interaction Between Liver and Adipose Tissue}

Chronic oversupply of nutrients to the adipose tissue can eventually lead to adipocyte dysfunction and an inability to store these excess nutrients. This can evoke increased ectopic lipid deposition in other tissues including liver, skeletal muscle, and heart (81). ATMs can directly increase adipose tissue lipolysis through the release of specific cytokines, including TNF $\alpha$, IFN$\gamma$, and IL-1 $\beta(82,83)$ and thereby enhance the lipid flux to the liver. Further evidence for adipose-liver interactions comes from a recent study demonstrating that acute adipocyte death induces rapid CCR2 $2^{+}$macrophage infiltration into the adipose tissue. These macrophages enhance lipolysis via modulation of epinephrine and norepinephrine levels. Interestingly, this wave of adipocyte death also causes acute secondary liver injury which is dependent upon $\mathrm{CCR} 2^{+}$macrophage infiltration into the liver (84). Although fatty acids serve as one important mediator that links adipose tissue and liver, the crosstalk between these tissues goes beyond lipids. In addition, obese adipose tissue secretes a range of other nutrients, adipokines, and inflammatory molecules which can promote pathogenic events in the liver (85). This is exemplified by leptin, an adipokine that signals via hepatic macrophages to induce hepatic stellate cell activation and liver fibrosis (86).

Inflamed adipose tissue has also been associated with the development of NASH. Moreover, there is increasing evidence that adipose inflammation is directly linked to liver pathology. For example, surgical removal of epididymal adipose tissue in HFD-induced obesity was shown to reduce circulating inflammatory mediators and attenuate NASH progression (87). In addition, ATM expansion and expression of inflammatory mediators precedes hepatic inflammation in HFD-induced obesity, suggesting that macrophage responses in the adipose tissue may be upstream of NASH development. In line with this concept, data from a recent study demonstrated that transplanting adipose tissue from obese mice increased liver macrophage content and NASH severity compared to adipose tissue from lean mice. This response was attenuated when ATMs were depleted from the adipose tissue prior to transplantation (88). Although most studies have focused on how adipose inflammation can modulate the pathogenesis of $\mathrm{NASH}$, the interaction between liver and adipose inflammation is likely reciprocal. In fact, it has been demonstrated that preventive depletion of liver macrophages inhibits adipose tissue inflammation upon HFD feeding (89). The interplay between adipose and hepatic inflammation is likely also relevant in human NASH. This is supported by data showing that the expression of several inflammatory mediators, including $\mathrm{TNF} \alpha$, IL-8, and CCL-3, as well as ATM number in the adipose tissue is associated with NAFLD and NASH severity and liver fibrosis in patients (90-92).

Future studies investigating the crosstalk between the macrophages in liver and adipose tissue during obesity are anticipated to reveal additional mediators linking adipose tissue inflammation and NASH. In particular, the role of macrophagesecreted exosomes and their cargo are now recognized as important mediators of crosstalk between macrophages in distant tissues as well as between macrophages and parenchymal cells. In this respect, ATMs from obese murine adipose tissue have been shown to secrete exosomes containing miRNA-29a and miRNA$155(93,94)$. These secreted exosomes are taken up by adipocytes but also by other tissues, including liver and skeletal muscle. This was shown to result in impaired glucose tolerance and decreased insulin sensitivity. Thus, exosome secretion may be an important paracrine and autocrine signal by which tissue macrophages can influence local and systemic metabolism. In addition to macrophage-derived exosomes, these vesicles are also secreted by adipocytes and hepatocytes. Importantly, adipocyte-derived exosomes have been shown to affect macrophage activation and polarization, with predominantly an increase in inflammatory cytokine production $(95,96)$. In addition, when exosomes isolated from VAT of obese patients were applied to hepatocyte or hepatic stellate cell lines in vitro, uptake of these vesicles induced an upregulation of the TGF $\beta$ signaling pathway and expression of genes related to extracellular matrix deposition (97). This indicates a possible direct role of adipose tissue-derived exosomes in NASH progression, although future studies will be needed to determine the extent to which this occurs in vivo. As studies have shown that obesity is associated with increased circulating extracellular vesicles, this may be of particular importance in obesity and the development of its metabolic complications (98). Dissecting the molecules and pathways involved in inter-organ crosstalk in the metabolic syndrome has the potential to drive the discovery of new therapeutic targets.

\section{METABOLIC REPROGRAMMING OF MACROPHAGE FUNCTION}

\section{Glucose Metabolism}

Increased glucose uptake and upregulation of glycolysis, the so-called glycolytic switch, is associated with proinflammatory macrophage activation and is important for classical inflammatory macrophage effector functions including phagocytosis, pro-inflammatory cytokine production and reactive oxygen species (ROS) generation $(99,100)$. The rapid increase in glucose uptake in activated macrophages is facilitated by upregulation of glucose transporter 1 (GLUT1). In some instances, GLUT1 overexpression has been shown to increase glucose metabolism and augment the secretion of inflammatory mediators and ROS production (100). However, these findings have not been recapitulated in primary macrophages where GLUT1 overexpression does not augment inflammatory cytokine release, despite increasing glucose uptake and utilization (101). Thus, glucose metabolism and macrophage inflammation are related but dissociable responses, suggesting the interplay between glycolysis/glycolytic metabolites and inflammatory signaling pathways ultimately shapes cell function. In the context of metabolic disease, GLUT1 expression is upregulated in both adipose tissue and liver of HFD-fed rats and colocalizes specifically with macrophages present in CLS in both organs (100). Whether perturbations of GLUT1 impact ATM-mediated functions and/or insulin resistance is not known.

The NLRP3 inflammasome has recently been recognized as an important driver of inflammation in many complications 
of obesity including atherosclerosis, insulin resistance, and NASH $(102,103)$. In macrophages, NLRP3 complex assembly and IL- $1 \beta$ transcription are both sensitive to perturbations in glucose metabolism. As an example, hexokinase-1-dependent glycolysis promotes NLRP3 inflammasome activation and IL$1 \beta$ secretion, a response mediated by mTORC1 (104). In addition, the transcription factor Hypoxia-inducing factor 1- $\alpha$ (HIF1 $\alpha$ ) appears to be another important link between glucose metabolism and NLRP3 inflammasome regulation. In activated macrophages HIF1 $\alpha$ is stabilized by the tricarboxylic acid cycle (TCA) cycle intermediate succinate, which accumulates in part due to increased glycolytic flux $(105,106)$. Subsequently, HIF$1 \alpha$ induces the expression of GLUT1 and other glycolytic genes (107) and may directly upregulate gene expression of IL-1 $\beta$ via PKM2 $(105,108,109)$. The relevance of this pathway in metabolic disease is supported by data demonstrating that mice lacking HIF1 $\alpha$ are protected against HFD-induced adipose tissue inflammation (110). Moreover, there is evidence that HIF- $1 \alpha$ is upregulated in macrophages in both mice and humans with NASH (111). In addition to the inflammasome, glycolytic flux can also influence the production of other proinflammatory cytokines, such as TNF $\alpha$. This can occur via the bifunctional enzyme glyceraldehyde 3-phosphate dehydrogenase (GAPDH), which negatively regulates TNF $\alpha$ expression by inhibiting its translation. As such, when the rate of glycolysis increases GAPDH is recruited for its metabolic function and the break on TNF $\alpha$ translation is released (112). Together, these data demonstrate a key role for glycolytic enzymes and intermediates in the regulation of macrophage-mediated inflammatory responses.

Upregulation of glucose uptake also feeds substrate into the pentose phosphate pathway (PPP) which is also upregulated in inflammatory macrophages (113). The PPP is important for the generation of amino acids and ribose for protein and nucleotide synthesis as well as NADPH, which is essential for NADPH oxidase-mediated ROS production, fatty acid synthesis, and generation of glutathione. The regulation of the PPP is mediated by carbohydrate kinase-like protein (CARKL) in primary murine and human macrophages. CARKL is suppressed in response to LPS activation, resulting in increased flux through the PPP (114). To date the inflammatory and metabolic effects of inhibiting flux through the PPP in ATMs or liver macrophages is less well-understood.

Although increased glycolytic flux is a hallmark of inflammatory macrophage activation, glycolysis is also required for alternatively macrophage activation. Mechanistically, it has been shown that IL-4 and M-CSF activate mTORC2, which subsequently upregulates glycolysis via IRF4 (115). However, unlike inflammatory macrophages where the products of glycolysis are frequently channeled away from the mitochondria, in alternative activation glycolysis supports the TCA cycle and mitochondrial oxidative phosphorylation (OXPHOS). In line with this notion, the inhibition of glycolysis with 2-deoxyglucose (2-DG) reduced OXPHOS and attenuated early M2 marker expression in response to IL-4 (116). However, there is also evidence that 2-DG can decrease OXPHOS directly which may also explain some of these findings (117).
In summary, although glucose metabolism is associated with classical inflammatory macrophage activation, it is also required for alternative macrophage activation. Thus, selective modulation of glucose metabolism is a more viable approach for disrupting macrophage inflammation. Further investigation will also be necessary to unravel the complex interplay between macrophage glucose handling and the hyperglycemia that frequently exists in states of obesity and insulin resistance.

\section{Lipid Metabolism}

In contrast to the stimulation of glycolytic metabolism that occurs in inflammatory macrophages, increased lipid uptake and oxidation is a hallmark of alternative macrophage activation induced by IL-4. In this system, IL-4 increases mitochondrial fatty acid oxidation (FAO) and this metabolic response appears to be necessary for macrophages to acquire an M2 phenotype (118). This is supported by data demonstrating that inhibiting FAO or OXPHOS with compounds like etomoxir, oligomycin, or the mitochondrial uncoupler FCCP, attenuates the expression of classic M2 polarization markers (e.g., arginase, YM1, Rentla) $(118,119)$. Mechanistically, the metabolic reprogramming induced by IL-4 is dependent upon the transcriptional effects of STAT6 and PGC-1 $\beta$ (119). The nuclear receptor transcription factors PPAR $\gamma$ and PPAR $\beta / \delta$ have also been reported to contribute to the upregulation of genes involved in lipid uptake, FAO, and mitochondrial OXPHOS. In general, the source of fatty acids to fuel this response derives from exogenous triacylglycerol substrate, which is taken up via scavenger receptor CD36 and broken down by lysosomal acid lipase (LAL)-mediated lipolysis (118). In line with this, attenuation of lipolysis by orlistat decreases oxidative respiration and reduces alternative macrophage polarization. Moreover, orlistat or knockout of LAL has been shown to decrease oxidative respiration and reduce alternative macrophage polarization. Although exogenous fatty acids appear to be the predominant source of lipid, triglyceride derived from fatty acid synthase can also be used to fuel OXPHOS in some circumstances. Despite strong evidence that IL-4 mediated alternative activation of macrophages requires FAO, whether these lipid metabolic pathways are as important for reparative macrophage phenotypes in vivo is not known.

Other lipid metabolic regulators that have been shown to influence macrophage inflammatory function include fatty acid transporter protein FATP1 and FABP4/5 $(120,121)$. Deletion of FATP1 in cultured macrophages induces a metabolic switch toward glycolysis and primes macrophages for proinflammatory functions. In vivo, loss of FATP1 in bone marrow derived cells was associated with increased HFD-induced weight gain, glucose intolerance, and adipose tissue inflammation. In contrast, deletion or inhibition of FABP4 or FABP5 attenuates lipid-induced inflammation and improves metabolic phenotypes in vivo (121). Further mechanistic links between $\mathrm{FAO}$ and macrophage function came from experiments in which macrophages were engineered to overexpress carnitine palmitoyl transferase (CPT)-1. In this system, CPT1 overexpression increased FAO, decreased triglyceride content and dampened pro-inflammatory cytokine production (122). Together these 
data indicate that modulating lipid handling has potential as a strategy to shift macrophage function in obesity related diseases.

The regulation of cellular lipid metabolism is also controlled by several key nuclear receptor transcription factors and their coactivators. Peroxisome proliferator-activated receptors (PPARs) act as lipid sensors and modulate both lipid storage and utilization (123). Both PPAR $\beta / \delta$ and PPAR $\gamma$ have been shown to influence macrophage polarization, as ablation of either inhibits IL-4 stimulated alternative macrophage activation (76, $124,125)$. With HFD feeding, myeloid-specific PPAR $\gamma$ knockout mice have increased weight gain, adiposity, and glucose intolerance, which was paralleled by decreased expression of classic alternative macrophage activation markers and increased adipose tissue inflammation (124). Myeloid-specific deletion of $\mathrm{PPAR} \beta / \delta$ also resulted in increased weight gain, adiposity, and insulin resistance upon HFD feeding. In both liver and adipose tissue, proinflammatory gene expression was increased and M2 marker expression reduced (125). In addition, steatosis in the liver was more severe in the knockout animals. Together this data supports the idea that targeting lipid metabolic pathways by enhancing PPAR activity in macrophages could be utilized as a strategy to modulate obesity complications. It is also worth noting that disrupting PPAR activity in macrophages may also accelerate the development of obesity itself.

Macrophages also express other transcription factors that regulate cholesterol and lipid metabolism including liver $\mathrm{X}$ receptors (LXR), CCAAT enhancer binding proteins (C/EBPs), and sterol regulatory element binding proteins (SREBPs). Of interest, KCs express high levels of $\operatorname{LXR} \alpha$, which acts as cholesterol sensor and regulates intracellular cholesterol levels by expression of cholesterol efflux transporters ABCA1 and ABCG1 $(126,127)$ as well as apolipoproteins as ApoE and ApoC (128, 129). Interestingly, LXR is necessary for the maintenance of KCs in the liver (130). In vitro studies have shown that ligands of LXR receptors inhibit expression of inflammatory mediators as iNOS, COX-2, MMP-9, and IL-6 (131) and can upregulate expression of arginase II which potentiates anti-inflammatory effects (132). SREBPs are considered master regulators of cholesterol and lipid synthesis. In general, they coordinate the balance between lipid uptake and de novo lipogenesis/cholesterol biosynthesis. Besides their role in lipogenesis, SREBP1a enhances expression of nlrpla, a key component of inflammasome activation and IL$1 \beta$ release in macrophages in vitro (133). Deletion of SREBP1a in cultured macrophages results in increased inflammatory gene expression following TLR4 stimulation, likely due to a lack of anti-inflammatory unsaturated fatty acid production (134). These findings argue that LXRs and SREBPs link lipid metabolism to macrophage inflammatory function; however, the role of these pathways in obesity-related inflammation is less clear.

$\mathrm{C} / \mathrm{EBP} \alpha$ and $\mathrm{C} / \mathrm{EBP} \beta$ are also widely expressed in macrophages and have been implicated in regulating glucose and lipid metabolism (135). C/EBP $\beta$ appears to promote alternative macrophage activation in skeletal muscle macrophages (136). Germane to this finding, myeloid-specific knock-out of $\mathrm{C} / \mathrm{EBP} \alpha$ led to increased adiposity in chow-fed mice, indicating an important role of macrophage $\mathrm{C} / \mathrm{EBP} \alpha$ in energy homeostasis under physiological conditions (137). Upon $\mathrm{HFD}, \mathrm{C} / \mathrm{EBP} \alpha$ deletion in mice protected against diet-induced insulin resistance mainly due to preserved skeletal muscle insulin sensitivity. Macrophage polarization markers revealed both M1 and M2 markers to be downregulated (137). Similarly, HFD-fed mice transplanted with bone-marrow lacking C/EBP $\beta$ had reduced expression of inflammatory markers and decreased macrophage content in adipose tissue. This inflammatory phenotype was associated with improved insulin sensitivity. Of relevance, $\mathrm{C} / \mathrm{EBP} \beta$ can induce the expression of PPAR $\gamma$ and $\operatorname{LXR} \alpha$ in primary macrophages; however, it is unclear if this is related to the detrimental metabolic effects observed in $\mathrm{C} / \mathrm{EBP} \beta \mathrm{KO}$ mice (138).

Recently, the requirement of FAO for alternative macrophage activation has been questioned. Primary macrophages lacking CPT2 have reduced rates of FAO, but have no defect in IL4 -induced alternative activation (139). In addition, blocking FAO oxidation by use of etomoxir does not affect IL-4-induced differentiation of primary human macrophages. In fact, in some circumstances FAO can potentiate pro-inflammatory responses including inflammasome activation. In this respect, FAO via CPT1 can promote activation of the NLRP3 inflammasome via effects on by NADPH oxidase 4 (NOX4) (140). This can be stimulated by fatty acids as palmitate and may require mitochondrial ROS production $(141,142)$. In line with this data, deletion of PPAR $\gamma$ in macrophages leads to a reduction IL-1 $\beta$ production and release in response to NLRP3 activators, an effect mediated by IFN- $\beta$ (143). Thus, FAO and resultant metabolic byproducts play a complex role in the regulation of macrophage reparative and inflammatory functions. Together these data demonstrate a multifaceted relationship between lipid metabolism and inflammation in metabolic disease. Regardless, these proof-of-concept studies provide evidence that lipid metabolic pathways may be viable targets for modulating macrophage function.

\section{TCA Cycle}

In addition to enhanced glycolysis, a disrupted TCA cycle is an important feature of classically activated macrophages (113). The "broken" TCA cycle results in decreased production of $\alpha$-ketoglutarate and an accumulation of citrate and succinate. Citrate accumulates as a result of reduced isocitrate dehydrogenase (Idh1) expression in inflammatory macrophages. Toll-like receptor stimulation also induces the expression of the mitochondrial citrate carrier (CIC) in macrophages. CIC regulates citrate efflux from mitochondria to cytosol where it can be used for de novo lipogenesis, production of proinflammatory lipid mediators (prostaglandin E2) and synthesis of NO (144). Citrate is also converted to acetyl-CoA by ATP-dependent citrate lyase (ACLY) and this can enhance pro-inflammatory gene expression via histone acetylation (145).

Pyruvate dehydrogenase kinase (PDK) has been postulated to be important for M1 polarization as it reduces entry of carbons from glycolysis into the TCA cycle by inhibiting pyruvate dehydrogenase (PHD). Indeed, pharmacological inhibition of PDK2 and-4 blocks inflammatory activation of cultured macrophages (146). Myeloid-specific ablation of PDK2/4 using 
a bone-marrow transplant approach led to reduced weight gain, improved glucose tolerance and reduced adiposity and liver fat when fed a HFD. In addition, HFD-induced ATM accumulation as well as adipose tissue inflammatory expression was diminished. On the contrary, recent data has also shown that glucose-derived pyruvate conversion to mitochondrial acetyl-CoA by pyruvate dehydrogenase (PHD) is maintained during LPS stimulation and is important for pro-inflammatory macrophage activation as it fuels citrate production (147).

Citrate can also serve as a precursor for itaconate, which is produced by the enzyme immunoresponsive gene 1 (Irg1). This metabolite subsequently inhibits succinate dehydrogenase (SDH) and elevates succinate levels $(148,149)$. Succinate stabilizes HIF$1 \alpha$, which as mentioned above upregulates IL- $1 \beta$ production (105). Moreover, SDH is also a subunit of complex II of the electron transport chain, where oxidation of succinate is coupled to reduction of ubiquinone. Increased oxidation of succinate by $\mathrm{SDH}$ results in production of mitochondrial ROS, also supporting HIF- $1 \alpha$ stabilization and inflammatory gene expression (150). In more recent data it has been shown that succinate is also a ligand for the succinate receptor SUCNR1. This is relevant as activated macrophages can secrete succinate, which influences macrophage polarization in both an autocrine and paracrine manner via SUCNR1 $(151,152)$. The importance of this signaling pathway was demonstrated by creating mice with a myeloid-specific knock-out of SUCNR1. These animals were more susceptible to diet-induced obesity and had worsened glucose tolerance (152). This was paralleled by an increased inflammatory molecular signature in ATMs of these mice, suggesting that extracellular succinate might play a role in dampening inflammatory responses. Analysis of WAT explants from lean and obese subjects also showed this succinateSUCNR1 pathway was disturbed in obese human WAT. In summary, TCA cycle metabolites are important determinants of metabolic programming through their allosteric properties and their ability to directly activate signaling pathways. This "metabokine" function of TCA intermediates has been proposed to be an important regulatory mechanism of inflammatory responses (153). Harnessing the signaling properties of TCA cycle intermediates holds promise as a tool for modulating macrophage metabolism in disease.

\section{Amino Acid Metabolism}

Glutamine is one the most important amino acids to fuel macrophage activation. Interestingly, glutamine has different metabolic fates in M1 and M2-like macrophages. In inflammatory macrophages, glutamine-derived glutamate fuels in to the TCA cycle for succinate production via GABA production (105). Hence it contributes to the effects of succinate accumulation on pro-inflammatory macrophage polarization. Furthermore, glutamine has been shown to enhance macrophage lipotoxicity, as removal of glutamine from the nutrient microenvironment attenuates macrophage cell death and inflammasome activation upon exposure to excess saturated fatty acids (154). M2/IL-4 stimulated macrophages also have increased glutamine levels, which occurs predominantly via the activity of glutamine synthetase (GS) (155). Glutamine also contributes to M2 polarization via glutamine-derived $\alpha$-ketoglutarate, which is essential for FAO as well as epigenetic programming during alternative macrophage activation (156). Thus far, most studies on the effects of glutamine on the polarization of macrophages have been limited to cultured murine macrophages. Although patients with obesity and diabetes have been shown to have reduced serum glutamine levels, it remains to be further studied if and to what extent glutamine metabolism affects tissue macrophage polarization in both mice and humans (157).

The amino acid L-arginine also has divergent roles in macrophage polarization. L-arginine is an essential precursor for the production of NO via iNOS, which is induced during inflammatory macrophage activation. On the other hand, metabolism of L-arginine by arginase is associated with alternative macrophage activation and appears important for

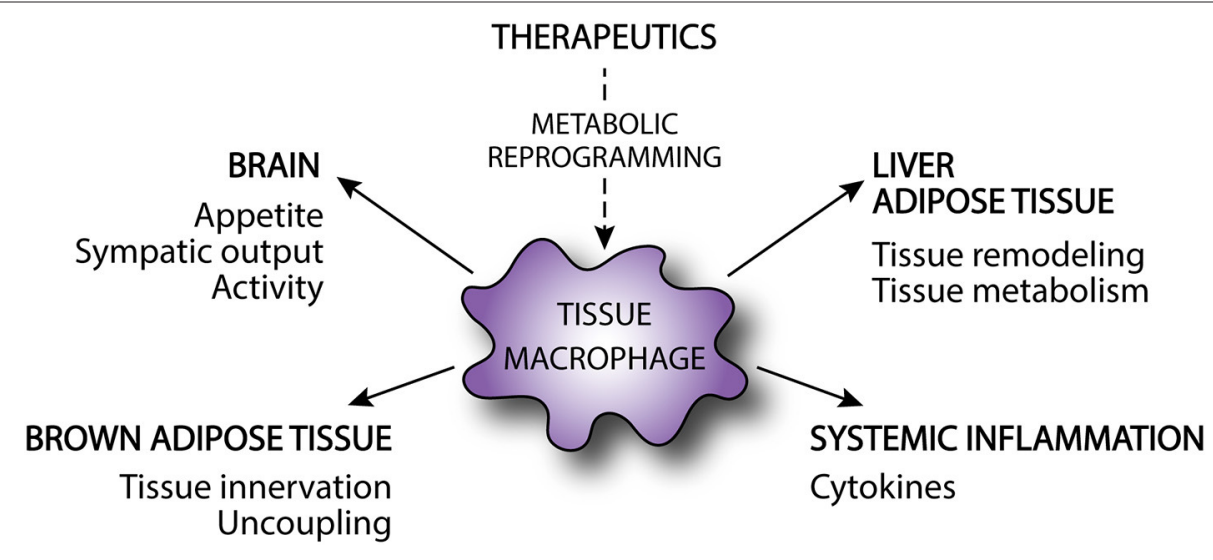

FIGURE 2 | Modulation of obesity and metabolic disorders by tissue macrophages. Tissue macrophages can affect obesity and the development of associated metabolic disorders by affecting energy intake and energy expenditure via brain, brown adipose tissue, and skeletal muscle. Alternatively, tissue macrophages modulate development of metabolic disorders in obesity by regulating adipose tissue and liver metabolism and tissue remodeling as well as by contributing the systemic inflammation. Metabolic reprogramming via targeted therapeutics may alter macrophage activation and subsequently improve metabolic disease. 


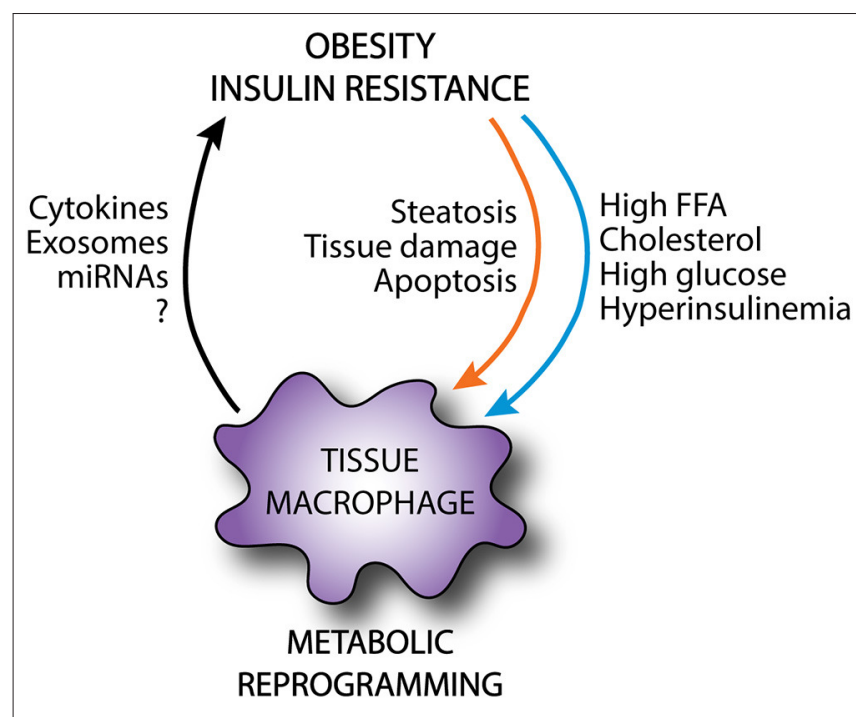

FIGURE 3 | Metabolic reprogramming of tissue macrophages in obesity. In obesity, tissue macrophages are exposed to an excessive and altered nutrient environment and receive a variety of danger signals from damaged parenchymal cells. This can rewire the metabolic programming of tissue macrophages, altering the activation state of these cells. Although these macrophages may exert protective functions as shielding and clearance of apoptotic cells, they can also release local and systemic mediators that can further exacerbate metabolic disease.

tissue repair (158). It is likely that other amino acids can modulate macrophage biology and this is an area that will require further investigation.

\section{Macrophage Regulation of Obesity and Insulin Resistance}

As reviewed above, targeting important metabolic pathways in macrophages has the potential to alter not only macrophage function, but also systemic metabolism. However, the exact mechanisms by which tissue macrophages regulate whole-body metabolism are largely unknown and this remains an important knowledge gap in the field. As discussed above, it is clear that macrophages can interact with parenchymal cells in the adipose and liver in ways that modulate systemic glucose homeostasis (Figure 2) (159). In addition, the release of pro-inflammatory cytokines from metabolically activated macrophages can also promote skeletal muscle and hepatic insulin resistance. However, there is also evidence that whole-body metabolism can be modulated via inflammatory signaling that occurs locally in the brain (Figure 2). As an example, it was recently shown that HFD causes accumulation of pro-inflammatory microglia in the brain of mice. Moreover, pharmacologic or genetic disruption of NF$\kappa \mathrm{B}$-dependent microglial activation decreased hyperphagia and reduced diet-induced obesity (160). The exact pathways through which microglia influence energy balance are unclear, but could be related to changes in appetite, activity level, or sympathetic nervous output. Of importance, sympathetic output regulates energy expenditure in part by modulating brown adipose tissue (BAT) activity. Tissue resident macrophages in BAT also contribute to the metabolism of catecholamines, which influences thermogenesis and energy homeostasis (Figure 2) (161).

\section{CONCLUSIONS AND FUTURE PERSPECTIVES}

Obesity exposes tissue macrophages to a microenvironment that consists of excess nutrients as well as stress signals from damaged and apoptotic parenchymal cells. These environmental cues can activate macrophages and rewire their cellular metabolism in ways that may promote maladaptive inflammation and macrophage dysfunction. Macrophage activation may initially be beneficial to facilitate the removal of apoptotic cells, clear excess lipids, and restore tissue homeostasis. However, aberrant metabolic reprogramming of macrophages in the setting of sustained lipid-induced tissue injury likely provokes pathologic macrophage phenotypes. When this occurs the macrophage secretome may act locally and/or systemically to drive metabolic disease development (Figure 3). This concept is particularly true in tissues that are faced with a high metabolic burden in obesity, such as adipose tissue and liver. In order to harness the therapeutic potential of re-programming macrophage metabolism for human disease, it will be essential to dissect the mechanistic pathways by which macrophages improve or worsen obesity-related complications.

Although it is established that perturbing macrophage cellular metabolism can improve metabolic disease phenotypes, the precise cellular and molecular details remain poorly understood. In part this is due to the fact that much of the data in this field comes from knockout or overexpression of key metabolic genes in the context of in vitro models or non-selective myeloid knock-out systems. Ultimately, elucidating the heterogeneity of macrophage populations in different organs and their relation to metabolic disease will allow more specific therapeutic targeting. However, our understanding of this has been limited by the lack of tissue-specific macrophage markers to identify and manipulate resident macrophages in different tissues. As such, most studies have used generic myeloid knock-out models, such as LysM-Cre or bone-marrow transplantation. The identification of unique markers of tissue macrophages through the use of sophisticated unbiased approaches such as scRNA-seq, has the potential to open up new avenues to investigate the role of distinct macrophage subsets in tissue and whole-body metabolism. As an example, it has recently been shown that liver resident KCs uniquely express the surface receptors Tim 4 and Clec4f. This discovery facilitated the development of Clec4f-Cre transgenic mice, which will enable the study $\mathrm{KC}$ specific functions in liver pathology and metabolic disease (130).

Another challenge to advancing this field relates to the impact of variations in genetic background, microbiota composition, and research environment on phenotypes in metabolic disease research $(162,163)$. As a consequence, it is commonplace that genetic and pharmacologic disruption of inflammatory/metabolic pathways in macrophages produce contradictory results. In order to minimize the influence of these variables it is critical to utilize littermate controls and to 
co-house wild type and knockout mice in the same cage. The same principle holds true for pharmacologic intervention where mice from both treatment groups should be mixed together in cages. These interventions will reduce the influence of geneenvironment interactions that confound data interpretation. In addition, the use of human systems to validate mouse model observations will be vital to improve the identification of relevant therapeutic targets for modulating macrophage metabolism.

The pathogenesis of obesity-related metabolic disorders, such as insulin resistance is highly complex and involves metabolic perturbations in multiple organs. Tissue macrophages secrete a plethora of factors that may affect macrophage polarization and subsequently tissue function in distant organs. Evidence already exists to support the concept that adipose tissue macrophages can direct relevant pathological events in the liver in the setting of obesity. Conversely, it is attractive to hypothesize that signaling from liver macrophages to adipose tissue also occurs. It will be important to identify the key molecules involved in inter-organ crosstalk and to evaluate their effects on tissue macrophage biology.

The objective of this review was to discuss our current understanding of macrophage diversity in metabolically relevant tissues and to consider the intersection of these principles with the regulation of macrophage cellular metabolism. Although significant progress has been in these areas, further investigation

\section{REFERENCES}

1. Gautier EL, Yvan-Charvet L. Understanding macrophage diversity at the ontogenic and transcriptomic levels. Immunol Rev. (2014) 262:8595. doi: 10.1111/imr.12231

2. Gautier EL, Shay T, Miller J, Greter M, Jakubzick C, Ivanov S, et al. Geneexpression profiles and transcriptional regulatory pathways that underlie the identity and diversity of mouse tissue macrophages. Nat Immunol. (2012) 13:1118-28. doi: 10.1038/ni.2419

3. Bonnardel J, T'Jonck W, Gaublomme D, Browaeys R, Scott CL, Martens L, et al. Stellate cells, hepatocytes, and endothelial cells imprint the kupffer cell identity on monocytes colonizing the liver macrophage niche. Immunity. (2019) 51:638-54 e9. doi: 10.1016/j.immuni.2019.08.017

4. Sakai M, Troutman TD, Seidman JS, Ouyang Z, Spann NJ, Abe Y, et al. Liver-derived signals sequentially reprogram myeloid enhancers to initiate and maintain kupffer cell identity. Immunity. (2019) 51:655-70 e8. doi: 10.1016/j.immuni.2019.09.002

5. Baker AD, Malur A, Barna BP, Ghosh S, Kavuru MS, Malur AG, et al. Targeted PPAR $\gamma$ deficiency in alveolar macrophages disrupts surfactant catabolism. J Lipid Res. (2010) 51:1325-31. doi: 10.1194/jlr.M0 01651

6. Scott CL, Guilliams M. The role of kupffer cells in hepatic iron and lipid metabolism. J Hepatol. (2018) 69:1197-9. doi: 10.1016/j.jhep.2018.02.013

7. Xue J, Schmidt SV, Sander J, Draffehn A, Krebs W, Quester I, et al. Transcriptome-based network analysis reveals a spectrum model of human macrophage activation. Immunity. (2014) 40:274-88. doi: 10.1016/j.immuni.2014.01.006

8. Boutens L, Stienstra R. Adipose tissue macrophages: going off track during obesity. Diabetologia. (2016) 59:879-94. doi: 10.1007/s00125-016-3904-9

9. Martinez-Santibanez G, Lumeng CN. Macrophages and the regulation of adipose tissue remodeling. Annu Rev Nutr. (2014) 34:57-76. doi: 10.1146/annurev-nutr-071812-161113

10. Hassnain Waqas SF, Noble A, Hoang AC, Ampem G, Popp M, Strauss S, et al. Adipose tissue macrophages develop from bone marrow-independent and integration of these fields will be necessary to harness the therapeutic potential of re-programming macrophage metabolism in obesity and diabetes. In addition, defining the molecular basis of crosstalk between macrophages and parenchymal cells in adipose tissue, liver, and the brain will also require more study. Another important issue to resolve in this area is whether targeting macrophage metabolism can attenuate pathologic inflammation during obesity without disabling the fundamental roles of these immune cells in tissue repair and the maintenance of homeostasis. Eventually, the use of targeted small molecules or nanoparticles are attractive modalities to modulate macrophage function. Although there is much yet to be learned, metabolic targeting of macrophage biology holds promise as therapeutic strategy to modulate metabolic disease.

\section{AUTHOR CONTRIBUTIONS}

SD and JS conceptualized and wrote the manuscript.

\section{FUNDING}

This work was supported by NIH grants RO1 DK11003401 (JS) and ADA 118-IBS280 (JS). The funding agencies provided resources for scientific research, publication costs, and concept development relevant to this manuscript. progenitors in xenopus laevis and mouse. J Leukoc Biol. (2017) 102:84555. doi: 10.1189/jlb.1A0317-082RR

11. Waqas SFH, Hoang AC, Lin YT, Ampem G, Azegrouz H, Balogh L, et al. Neuropeptide FF increases M2 activation and self-renewal of adipose tissue macrophages. J Clin Invest. (2017) 127:2842-54. doi: 10.1172/ JCI90152

12. Yona S, Kim KW, Wolf Y, Mildner A, Varol D, Breker M, et al. Fate mapping reveals origins and dynamics of monocytes and tissue macrophages under homeostasis. Immunity. (2013) 38:79-91. doi: 10.1016/j.immuni.2013.05.008

13. Boulenouar S, Michelet X, Duquette D, Alvarez D, Hogan AE, Dold $\mathrm{C}$, et al. Adipose type one innate lymphoid cells regulate macrophage homeostasis through targeted cytotoxicity. Immunity. (2017) 46:27386. doi: 10.1016/j.immuni.2017.01.008

14. Weisberg SP, McCann D, Desai M, Rosenbaum M, Leibel RL, Ferrante AW Jr. Obesity is associated with macrophage accumulation in adipose tissue. $J$ Clin Invest. (2003) 112:1796-808. doi: 10.1172/JCI200319246

15. Xu H, Barnes GT, Yang Q, Tan G, Yang D, Chou CJ, et al. Chronic inflammation in fat plays a crucial role in the development of obesity-related insulin resistance. J Clin Invest. (2003) 112:1821-30. doi: 10.1172/JCI200319451

16. Harman-Boehm I, Bluher M, Redel H, Sion-Vardy N, Ovadia S, Avinoach E, et al. Macrophage infiltration into omental versus subcutaneous fat across different populations: effect of regional adiposity and the comorbidities of obesity. J Clin Endocrinol Metab. (2007) 92:22407. doi: 10.1210/jc.2006-1811

17. Ehrlund A, Acosta JR, Bjork C, Heden P, Douagi I, Arner P, et al. The cell-type specific transcriptome in human adipose tissue and influence of obesity on adipocyte progenitors. Sci Data. (2017) 4:170164. doi: 10.1038/sdata.2017.164

18. Cancello R, Henegar C, Viguerie N, Taleb S, Poitou C, Rouault C, et al. Reduction of macrophage infiltration and chemoattractant gene expression changes in white adipose tissue of morbidly obese subjects after surgery-induced weight loss. Diabetes. (2005) 54:227786. doi: $10.2337 /$ diabetes.54.8.2277 
19. Huber J, Kiefer FW, Zeyda M, Ludvik B, Silberhumer GR, Prager G, et al. CC chemokine and $\mathrm{CC}$ chemokine receptor profiles in visceral and subcutaneous adipose tissue are altered in human obesity. J Clin Endocrinol Metab. (2008) 93:3215-21. doi: 10.1210/jc.2007-2630

20. Krinninger P, Ensenauer R, Ehlers K, Rauh K, Stoll J, Krauss-Etschmann S, et al. Peripheral monocytes of obese women display increased chemokine receptor expression and migration capacity. J Clin Endocrinol Metab. (2014) 99:2500-9. doi: 10.1210/jc.2013-2611

21. Amano SU, Cohen JL, Vangala P, Tencerova M, Nicoloro SM, Yawe JC, et al. Local proliferation of macrophages contributes to obesityassociated adipose tissue inflammation. Cell Metab. (2014) 19:16271. doi: 10.1016/j.cmet.2013.11.017

22. Zheng C, Yang Q, Cao J, Xie N, Liu K, Shou P, et al. Local proliferation initiates macrophage accumulation in adipose tissue during obesity. Cell Death Dis. (2016) 7:e2167. doi: 10.1038/cddis.2016.54

23. Ramkhelawon B, Hennessy EJ, Menager M, Ray TD, Sheedy FJ, Hutchison $\mathrm{S}$, et al. Netrin-1 promotes adipose tissue macrophage retention and insulin resistance in obesity. Nat Med. (2014) 20:377-84. doi: 10.1038/ nm.3467

24. Cinti S, Mitchell G, Barbatelli G, Murano I, Ceresi E, Faloia E, et al. Adipocyte death defines macrophage localization and function in adipose tissue of obese mice and humans. J Lipid Res. (2005) 46:234755. doi: 10.1194/jlr.M500294-JLR200

25. Keuper M, Bluher M, Schon MR, Moller P, Dzyakanchuk A, Amrein K, et al. An inflammatory micro-environment promotes human adipocyte apoptosis. Mol Cell Endocrinol. (2011) 339:105-13. doi: 10.1016/j.mce. 2011.04 .004

26. Chawla A, Nguyen KD, Goh YP. Macrophage-mediated inflammation in metabolic disease. Nat Rev Immunol. (2011) 11:738-49. doi: 10.1038/nri3071

27. Nguyen MT, Favelyukis S, Nguyen AK, Reichart D, Scott PA, Jenn A, et al. A subpopulation of macrophages infiltrates hypertrophic adipose tissue and is activated by free fatty acids via Toll-like receptors 2 and 4 and JNK-dependent pathways. J Biol Chem. (2007) 282:3527992. doi: 10.1074/jbc.M706762200

28. Li P, Lu M, Nguyen MT, Bae EJ, Chapman J, Feng D, et al. Functional heterogeneity of CD11c-positive adipose tissue macrophages in diet-induced obese mice. J Biol Chem. (2010) 285:15333-45. doi: 10.1074/jbc.M110. 100263

29. Martinez FO, Gordon S. The M1 and M2 paradigm of macrophage activation: time for reassessment. F1000Prime Rep. (2014) 6:13. doi: $10.12703 / \mathrm{P} 6-13$

30. Lumeng CN, Bodzin JL, Saltiel AR. Obesity induces a phenotypic switch in adipose tissue macrophage polarization. J Clin Invest. (2007) 117:17584. doi: 10.1172/JCI29881

31. Lumeng CN, DelProposto JB, Westcott DJ, Saltiel AR. Phenotypic switching of adipose tissue macrophages with obesity is generated by spatiotemporal differences in macrophage subtypes. Diabetes. (2008) 57:3239-46. doi: 10.2337/db08-0872

32. Xu X, Grijalva A, Skowronski A, van Eijk M, Serlie MJ, Ferrante AW Jr. Obesity activates a program of lysosomal-dependent lipid metabolism in adipose tissue macrophages independently of classic activation. Cell Metab. (2013) 18:816-30. doi: 10.1016/j.cmet.2013.11.001

33. Hill DA, Lim HW, Kim YH, Ho WY, Foong YH, Nelson VL, et al. Distinct macrophage populations direct inflammatory versus physiological changes in adipose tissue. Proc Natl Acad Sci USA. (2018) 115:E5096. doi: 10.1073/pnas.1802611115

34. Jaitin DA, Adlung L, Thaiss CA, Weiner A, Li B, Descamps $\mathrm{H}$, et al. Lipid-associated macrophages control metabolic homeostasis in a Trem2-dependent manner. Cell. (2019) 178:686-98 e14. doi: 10.1016/j.cell.2019.05.054

35. Coats BR, Schoenfelt KQ, Barbosa-Lorenzi VC, Peris E, Cui C, Hoffman A, et al. Metabolically activated adipose tissue macrophages perform detrimental and beneficial functions during diet-induced obesity. Cell Rep. (2017) 20:3149-61. doi: 10.1016/j.celrep.2017.08.096

36. Raes G, Van den Bergh R, De Baetselier P, Ghassabeh GH, Scotton $\mathrm{C}$, Locati $\mathrm{M}$, et al. Arginase-1 and $\mathrm{Ym} 1$ are markers for murine, but not human, alternatively activated myeloid cells. J Immunol. (2005) 174:6561. doi: 10.4049/jimmunol.174.11.6561
37. Bourlier V, Zakaroff-Girard A, Miranville A, De Barros S, Maumus M, Sengenes C, et al. Remodeling phenotype of human subcutaneous adipose tissue macrophages. Circulation. (2008) 117:806-15. doi: 10.1161/CIRCULATIONAHA.107. 724096

38. Wentworth JM, Naselli G, Brown WA, Doyle L, Phipson B, Smyth GK, et al. Pro-inflammatory CD11c+CD206+ adipose tissue macrophages are associated with insulin resistance in human obesity. Diabetes. (2010) 59:1648-56. doi: 10.2337/db09-0287

39. Nakajima S, Koh V, Kua LF, So J, Davide L, Lim KS, et al. Accumulation of CD11c+CD163+ adipose tissue macrophages through upregulation of intracellular 11 $\beta$-HSD1 in human obesity. J Immunol. (2016) 197:373545. doi: 10.4049/jimmunol.1600895

40. Fjeldborg K, Pedersen SB, Moller HJ, Christiansen T, Bennetzen M, Richelsen B. Human adipose tissue macrophages are enhanced but changed to an anti-inflammatory profile in obesity. J Immunol Res. (2014) 2014:309548. doi: 10.1155/2014/309548

41. Zeyda M, Farmer D, Todoric J, Aszmann O, Speiser M, Gyori G, et al. Human adipose tissue macrophages are of an anti-inflammatory phenotype but capable of excessive pro-inflammatory mediator production. Int J Obes. (2007) 31:1420-8. doi: 10.1038/sj.ijo.0803632

42. Kratz M, Coats BR, Hisert KB, Hagman D, Mutskov V, Peris E, et al. Metabolic dysfunction drives a mechanistically distinct proinflammatory phenotype in adipose tissue macrophages. Cell Metab. (2014) 20:61425. doi: 10.1016/j.cmet.2014.08.010

43. Gomez Perdiguero E, Klapproth K, Schulz C, Busch K, Azzoni E, Crozet $\mathrm{L}$, et al. Tissue-resident macrophages originate from yolk-sac-derived erythro-myeloid progenitors. Nature. (2015) 518:547-51. doi: 10.1038/ nature13989

44. Mass E, Ballesteros I, Farlik M, Halbritter F, Gunther P, Crozet L, et al. Specification of tissue-resident macrophages during organogenesis. Science. (2016) 353:6304. doi: 10.1126/science.aaf4238

45. Heymann F, Peusquens J, Ludwig-Portugall I, Kohlhepp M, Ergen C, Niemietz $P$, et al. Liver inflammation abrogates immunological tolerance induced by kupffer cells. Hepatology. (2015) 62:279-91. doi: 10.1002/hep.27793

46. Krenkel O, Tacke F. Liver macrophages in tissue homeostasis and disease. Nat Rev Immunol. (2017) 17:306-21. doi: 10.1038/nri.2017.11

47. Beattie L, Sawtell A, Mann J, Frame TCM, Teal B, de Labastida Rivera F, et al. Bone marrow-derived and resident liver macrophages display unique transcriptomic signatures but similar biological functions. J Hepatol. (2016) 65:758-68. doi: 10.1016/j.jhep.2016.05.037

48. Scott CL, Zheng F, De Baetselier P, Martens L, Saeys Y, De Prijck S, et al. Bone marrow-derived monocytes give rise to self-renewing and fully differentiated kupffer cells. Nat Commun. (2016) 7:10321. doi: 10.1038/ ncomms 10321

49. MacParland SA, Liu JC, Ma XZ, Innes BT, Bartczak AM, Gage BK, et al. Single cell RNA sequencing of human liver reveals distinct intrahepatic macrophage populations. Nat Commun. (2018) 9:4383. doi: 10.1038/s41467-01806318-7

50. Ramachandran P, Dobie R, Wilson-Kanamori JR, Dora EF, Henderson BEP, Luu NT, et al. Resolving the fibrotic niche of human liver cirrhosis at single-cell level. Nature. (2019) 575:512-8. doi: 10.1101/766113

51. Hardy T, Oakley F, Anstee QM, Day CP. Nonalcoholic fatty liver disease: pathogenesis and disease spectrum. Annu Rev Pathol. (2016) 11:45196. doi: 10.1146/annurev-pathol-012615-044224

52. Kiki I, Altunkaynak BZ, Altunkaynak ME, Vuraler O, Unal D, Kaplan S. Effect of high fat diet on the volume of liver and quantitative feature of kupffer cells in the female rat: a stereological and ultrastructural study. Obes Surg. (2007) 17:1381-8. doi: 10.1007/s11695-007-9219-7

53. Tosello-Trampont AC, Landes SG, Nguyen V, Novobrantseva TI, Hahn YS. Kuppfer cells trigger nonalcoholic steatohepatitis development in diet-induced mouse model through tumor necrosis factor- $\alpha$ production. J Biol Chem. (2012) 287:40161-72. doi: 10.1074/jbc.M112. 417014

54. de Meijer VE, Sverdlov DY, Le HD, Popov Y, Puder M. Tissuespecific differences in inflammatory infiltrate and matrix metalloproteinase expression in adipose tissue and liver of mice with diet-induced 
obesity. Hepatol Res. (2012) 42:601-10. doi: 10.1111/j.1872-034X.2011. 00960.x

55. Clementi AH, Gaudy AM, van Rooijen N, Pierce RH, Mooney RA. Loss of kupffer cells in diet-induced obesity is associated with increased hepatic steatosis, STAT3 signaling, and further decreases in insulin signaling. Biochim Biophys Acta. (2009) 1792:1062-72. doi: 10.1016/j.bbadis.2009.08.007

56. Stienstra R, Saudale F, Duval C, Keshtkar S, Groener JE, van Rooijen $\mathrm{N}$, et al. Kupffer cells promote hepatic steatosis via interleukin-1 $\beta$ dependent suppression of peroxisome proliferator-activated receptor $\alpha$ activity. Hepatology. (2010) 51:511-22. doi: 10.1002/hep.23337

57. Neyrinck AM, Cani PD, Dewulf EM, De Backer F, Bindels LB, Delzenne NM. Critical role of kupffer cells in the management of diet-induced diabetes and obesity. Biochem Biophys Res Commun. (2009) 385:3516. doi: 10.1016/j.bbrc.2009.05.070

58. Huang W, Metlakunta A, Dedousis N, Zhang P, Sipula I, Dube JJ, et al. Depletion of liver kupffer cells prevents the development of dietinduced hepatic steatosis and insulin resistance. Diabetes. (2010) 59:34757. doi: $10.2337 / \mathrm{db} 09-0016$

59. Leroux A, Ferrere G, Godie V, Cailleux F, Renoud ML, Gaudin F, et al. Toxic lipids stored by kupffer cells correlates with their pro-inflammatory phenotype at an early stage of steatohepatitis. J Hepatol. (2012) 57:1419. doi: 10.1016/j.jhep.2012.02.028

60. Cha JY, Kim DH, Chun KH. The role of hepatic macrophages in nonalcoholic fatty liver disease and nonalcoholic steatohepatitis. Lab Anim Res. (2018) 34:133-9. doi: 10.5625/lar.2018.34.4.133

61. Deng ZB, Liu Y, Liu C, Xiang X, Wang J, Cheng Z, et al. Immature myeloid cells induced by a high-fat diet contribute to liver inflammation. Hepatology. (2009) 50:1412-20. doi: 10.1002/hep.23148

62. Parker R, Weston CJ, Miao Z, Corbett C, Armstrong MJ, Ertl $\mathrm{L}$, et al. CC chemokine receptor 2 promotes recruitment of myeloid cells associated with insulin resistance in nonalcoholic fatty liver disease. Am J Physiol Gastrointest Liver Physiol. (2018) 314:G483-93. doi: 10.1152/ajpgi.00213.2017

63. Weisberg SP, Hunter D, Huber R, Lemieux J, Slaymaker S, Vaddi K, et al. CCR2 modulates inflammatory and metabolic effects of high-fat feeding. $J$ Clin Invest. (2006) 116:115-24. doi: 10.1172/JCI24335

64. Itoh M, Suganami T, Kato H, Kanai S, Shirakawa I, Sakai T, et al. $\mathrm{CD} 11 \mathrm{c}+$ resident macrophages drive hepatocyte death-triggered liver fibrosis in a murine model of nonalcoholic steatohepatitis. JCI Insight. (2017) 2:92902. doi: $10.1172 /$ jci.insight.92902

65. Zhang X, Han J, Man K, Li X, Du J, Chu ES, et al. CXC chemokine receptor 3 promotes steatohepatitis in mice through mediating inflammatory cytokines, macrophages and autophagy. J Hepatol. (2016) 64:160-70. doi: 10.1016/j.jhep.2015.09.005

66. Miura K, Yang L, van Rooijen N, Ohnishi H, Seki E. Hepatic recruitment of macrophages promotes nonalcoholic steatohepatitis through CCR2. Am J Physiol Gastrointest Liver Physiol. (2012) 302:G131021. doi: 10.1152/ajpgi.00365.2011

67. Miyachi Y, Tsuchiya K, Komiya C, Shiba K, Shimazu N, Yamaguchi S, et al. Roles for cell-cell adhesion and contact in obesity-induced hepatic myeloid cell accumulation and glucose intolerance. Cell Rep. (2017) 18:276679. doi: $10.1016 /$ j.celrep.2017.02.039

68. Guo Q, Furuta K, Lucien F, Sanchez LHG, Hirsova P, Krishnan A, et al. Integrin $\beta_{1}$-enriched extracellular vesicles mediate monocyte adhesion and promote liver inflammation in murine NASH. J Hepatol. (2019) 71:1193205. doi: 10.1016/j.jhep.2019.07.019

69. Zimmermann HW, Seidler S, Nattermann J, Gassler N, Hellerbrand C, Zernecke A, et al. Functional contribution of elevated circulating and hepatic non-classical CD14CD16 monocytes to inflammation and human liver fibrosis. PLoS ONE. (2010) 5:e11049. doi: 10.1371/journal.pone.00 11049

70. Krenkel O, Puengel T, Govaere O, Abdallah AT, Mossanen JC, Kohlhepp $\mathrm{M}$, et al. Therapeutic inhibition of inflammatory monocyte recruitment reduces steatohepatitis and liver fibrosis. Hepatology. (2018) 67:127083. doi: 10.1002/hep.29544

71. Itoh $M$, Kato $H$, Suganami $T$, Konuma $K$, Marumoto $Y$, Terai $S$, et al. Hepatic crown-like structure: a unique histological feature in non-alcoholic steatohepatitis in mice and humans. PLoS ONE. (2013) 8:e82163. doi: 10.1371/journal.pone.0082163

72. Chu PS, Nakamoto N, Ebinuma H, Usui S, Saeki K, Matsumoto A, et al. C-C motif chemokine receptor 9 positive macrophages activate hepatic stellate cells and promote liver fibrosis in mice. Hepatology. (2013) 58:33750. doi: 10.1002/hep.26351

73. Pradere JP, Kluwe J, De Minicis S, Jiao JJ, Gwak GY, Dapito DH, et al. Hepatic macrophages but not dendritic cells contribute to liver fibrosis by promoting the survival of activated hepatic stellate cells in mice. Hepatology. (2013) 58:1461-73. doi: 10.1002/hep.26429

74. Ramachandran P, Pellicoro A, Vernon MA, Boulter L, Aucott RL, Ali A, et al. Differential Ly-6C expression identifies the recruited macrophage phenotype, which orchestrates the regression of murine liver fibrosis. Proc Natl Acad Sci USA. (2012) 109:E3186-95. doi: 10.1073/pnas.1119 964109

75. Wan J, Benkdane M, Teixeira-Clerc F, Bonnafous S, Louvet A, Lafdil F, et al. M2 kupffer cells promote M1 kupffer cell apoptosis: a protective mechanism against alcoholic and nonalcoholic fatty liver disease. Hepatology. (2014) 59:130-42. doi: 10.1002/hep.26607

76. Odegaard JI, Ricardo-Gonzalez RR, Red Eagle A, Vats D, Morel CR, Goforth MH, et al. Alternative M2 activation of kupffer cells by PPARdelta ameliorates obesity-induced insulin resistance. Cell Metab. (2008) 7:496507. doi: 10.1016/j.cmet.2008.04.003

77. Papackova Z, Palenickova E, Dankova H, Zdychova J, Skop V, Kazdova $\mathrm{L}$, et al. Kupffer cells ameliorate hepatic insulin resistance induced by high-fat diet rich in monounsaturated fatty acids: the evidence for the involvement of alternatively activated macrophages. Nutr Metab. (2012) 9:22. doi: $10.1186 / 1743-7075-9-22$

78. Rensen SS, Slaats Y, Nijhuis J, Jans A, Bieghs V, Driessen $\mathrm{A}$, et al. Increased hepatic myeloperoxidase activity in obese subjects with nonalcoholic steatohepatitis. Am J Pathol. (2009) 175:1473-82. doi: 10.2353/ajpath.2009.080999

79. Devisscher L, Scott CL, Lefere S, Raevens S, Bogaerts E, Paridaens A, et al. Non-alcoholic steatohepatitis induces transient changes within the liver macrophage pool. Cell Immunol. (2017) 322:74-83. doi: 10.1016/j.cellimm.2017.10.006

80. Xiong X, Kuang H, Ansari S, Liu T, Gong J, Wang S, et al. Landscape of intercellular crosstalk in healthy and NASH liver revealed by single-cell secretome gene analysis. Mol Cell. (2019) 75:644-60 e5. doi: 10.1016/j.molcel.2019.07.028

81. Mittendorfer B. Origins of metabolic complications in obesity: adipose tissue and free fatty acid trafficking. Curr Opin Clin Nutr Metab Care. (2011) 14:535-41. doi: 10.1097/MCO.0b013e32834ad8b6

82. Laurencikiene J, van Harmelen V, Arvidsson Nordstrom E, Dicker A, Blomqvist L, Naslund E, et al. NF- $\kappa$ B is important for TNF- $\alpha$ induced lipolysis in human adipocytes. J Lipid Res. (2007) 48:106977. doi: 10.1194/jlr.M600471-JLR200

83. Ranjit S, Boutet E, Gandhi P, Prot M, Tamori Y, Chawla A, et al. Regulation of fat specific protein 27 by isoproterenol and TNF- $\alpha$ to control lipolysis in murine adipocytes. J Lipid Res. (2011) 52:221-36. doi: 10.1194/jlr. M008771

84. Kim SJ, Feng D, Guillot A, Dai S, Liu F, Hwang S, et al. Adipocyte death preferentially induces liver injury and inflammation through the activation of chemokine (C-C motif) receptor 2-positive macrophages and lipolysis. Hepatology. (2019) 69:1965-82. doi: 10.1002/hep.30525

85. Duwaerts CC, Maher JJ. Macronutrients and the adipose-liver axis in obesity and fatty liver. Cell Mol Gastroenterol Hepatol. (2019) 7:74961. doi: 10.1016/j.jcmgh.2019.02.001

86. Wang J, Leclercq I, Brymora JM, Xu N, Ramezani-Moghadam M, London RM, et al. Kupffer cells mediate leptin-induced liver fibrosis. Gastroenterology. (2009) 137:713-23. doi: 10.1053/j.gastro.2009. 04.011

87. Mulder P, Morrison MC, Wielinga PY, van Duyvenvoorde W, Kooistra T, Kleemann R. Surgical removal of inflamed epididymal white adipose tissue attenuates the development of non-alcoholic steatohepatitis in obesity. Int $J$ Obes. (2016) 40:675-84. doi: 10.1038/ijo.2015.226

88. Bijnen M, Josefs T, Cuijpers I, Maalsen CJ, van de Gaar J, Vroomen $M$, et al. Adipose tissue macrophages induce hepatic neutrophil 
recruitment and macrophage accumulation in mice. Gut. (2018) 67:1317-27. doi: 10.1136/gutjnl-2016-313654

89. Lanthier N, Molendi-Coste O, Cani PD, van Rooijen N, Horsmans Y, Leclercq IA. Kupffer cell depletion prevents but has no therapeutic effect on metabolic and inflammatory changes induced by a high-fat diet. FASEB J. (2011) 25:4301-11. doi: 10.1096/fj.11-189472

90. du Plessis J, van Pelt J, Korf H, Mathieu C, van der Schueren B, Lannoo $\mathrm{M}$, et al. Association of adipose tissue inflammation with histologic severity of nonalcoholic fatty liver disease. Gastroenterology. (2015) 149:635-48 e14. doi: 10.1053/j.gastro.2015.05.044

91. Tordjman J, Poitou C, Hugol D, Bouillot JL, Basdevant A, Bedossa P, et al. Association between omental adipose tissue macrophages and liver histopathology in morbid obesity: influence of glycemic status. J Hepatol. (2009) 51:354-62. doi: 10.1016/j.jhep.2009.02.031

92. Cancello R, Tordjman J, Poitou C, Guilhem G, Bouillot JL, Hugol D, et al. Increased infiltration of macrophages in omental adipose tissue is associated with marked hepatic lesions in morbid human obesity. Diabetes. (2006) 55:1554-61. doi: 10.2337/db06-0133

93. Ying W, Riopel M, Bandyopadhyay G, Dong Y, Birmingham A, Seo $\mathrm{JB}$, et al. Adipose tissue macrophage-derived exosomal miRNAs can modulate in vivo and in vitro insulin sensitivity. Cell. (2017) 171:372-84 e12. doi: 10.1016/j.cell.2017.08.035

94. Liu T, Sun YC, Cheng P, Shao HG. Adipose tissue macrophagederived exosomal miR-29a regulates obesity-associated insulin resistance. Biochem Biophys Res Commun. (2019) 515:352-8. doi: 10.1016/j.bbrc.2019. 05.113

95. Deng ZB, Poliakov A, Hardy RW, Clements R, Liu C, Liu Y, et al. Adipose tissue exosome-like vesicles mediate activation of macrophage-induced insulin resistance. Diabetes. (2009) 58:2498-505. doi: 10.2337/db09-0216

96. Kranendonk ME, Visseren FL, van Balkom BW, Nolte-'t Hoen EN, van Herwaarden JA, de Jager W, et al. Human adipocyte extracellular vesicles in reciprocal signaling between adipocytes and macrophages. Obesity. (2014) 22:1296-308. doi: 10.1002/oby.20679

97. Koeck ES, Iordanskaia T, Sevilla S, Ferrante SC, Hubal MJ, Freishtat RJ, et al. Adipocyte exosomes induce transforming growth factor beta pathway dysregulation in hepatocytes: a novel paradigm for obesity-related liver disease. J Surg Res. (2014) 192:268-75. doi: 10.1016/j.jss.2014.06.050

98. Kim A, Shah AS, Nakamura T. Extracellular vesicles: a potential novel regulator of obesity and its associated complications. Children. (2018) 5:E152. doi: 10.3390/children5110152

99. Pavlou S, Wang L, Xu H, Chen M. Higher phagocytic activity of thioglycollate-elicited peritoneal macrophages is related to metabolic status of the cells. J Inflamm. (2017) 14:4. doi: 10.1186/s12950-017-0151-x

100. Freemerman AJ, Johnson AR, Sacks GN, Milner JJ, Kirk EL, Troester MA, et al. Metabolic reprogramming of macrophages: glucose transporter 1 (GLUT1)-mediated glucose metabolism drives a proinflammatory phenotype. J Biol Chem. (2014) 289:7884-96. doi: 10.1074/jbc.M113.522037

101. Nishizawa T, Kanter JE, Kramer F, Barnhart S, Shen X, VivekanandanGiri A, et al. Testing the role of myeloid cell glucose flux in inflammation and atherosclerosis. Cell Rep. (2014) 7:356-65. doi: 10.1016/j.celrep. 2014.03.028

102. Rheinheimer J, de Souza BM, Cardoso NS, Bauer AC, Crispim D. Current role of the NLRP3 inflammasome on obesity and insulin resistance: a systematic review. Metabolism. (2017) 74:1-9. doi: 10.1016/j.metabol.2017.06.002

103. Grebe A, Hoss F, Latz E. NLRP3 inflammasome and the IL-1 pathway in atherosclerosis. Circ Res. (2018) 122:172240. doi: 10.1161/CIRCRESAHA.118.311362

104. Moon JS, Hisata S, Park MA, DeNicola GM, Ryter SW, Nakahira K, et al. mTORC1-induced HK1-dependent glycolysis regulates NLRP3 inflammasome activation. Cell Rep. (2015) 12:102-15. doi: 10.1016/j.celrep.2015.05.046

105. Tannahill GM, Curtis AM, Adamik J, Palsson-McDermott EM, McGettrick AF, Goel G, et al. Succinate is an inflammatory signal that induces IL-1 $\beta$ through HIF-1 $\alpha$. Nature. (2013) 496:238-42. doi: 10.1038/nature11986

106. Wang $\mathrm{T}$, Liu $\mathrm{H}$, Lian G, Zhang SY, Wang X, Jiang C. HIF1 $\alpha$ induced glycolysis metabolism is essential to the activation of inflammatory macrophages. Mediators Inflamm.

(2017) 2017:9029327. doi: 10.1155/2017/9029327

107. Fang HY, Hughes R, Murdoch C, Coffelt SB, Biswas SK, Harris AL, et al. Hypoxia-inducible factors 1 and 2 are important transcriptional effectors in primary macrophages experiencing hypoxia. Blood. (2009) 114:84459. doi: 10.1182/blood-2008-12-195941

108. Palsson-McDermott EM, Curtis AM, Goel G, Lauterbach MA, Sheedy FJ, Gleeson LE, et al. Pyruvate kinase M2 regulates Hif- $1 \alpha$ activity and IL- $1 \beta$ induction and is a critical determinant of the warburg effect in LPS-activated macrophages. Cell Metab. (2015) 21:65-80. doi: 10.1016/j.cmet.2014.12.005

109. Xie M, Yu Y, Kang R, Zhu S, Yang L, Zeng L, et al. PKM2-dependent glycolysis promotes NLRP3 and AIM2 inflammasome activation. Nat Commun. (2016) 7:13280. doi: 10.1038/ncomms13280

110. Takikawa A, Mahmood A, Nawaz A, Kado T, Okabe K, Yamamoto S, et al. HIF- $1 \alpha$ in myeloid cells promotes adipose tissue remodeling toward insulin resistance. Diabetes. (2016) 65:3649-59. doi: 10.2337/db16-0012

111. Wang X, de Carvalho Ribeiro M, Iracheta-Vellve A, Lowe P, Ambade A, Satishchandran A, et al. Macrophage-specific hypoxia-inducible factor- $1 \alpha$ contributes to impaired autophagic flux in nonalcoholic steatohepatitis. Hepatology. (2019) 69:545-63. doi: 10.1002/hep.30215

112. Millet P, Vachharajani V, McPhail L, Yoza B, McCall CE. GAPDH Binding to TNF- $\alpha$ mRNA contributes to posttranscriptional repression in monocytes: a novel mechanism of communication between inflammation and metabolism. J Immunol. (2016) 196:2541-51. doi: 10.4049/jimmunol.1501345

113. Jha AK, Huang SC, Sergushichev A, Lampropoulou V, Ivanova Y, Loginicheva E, et al. Network integration of parallel metabolic and transcriptional data reveals metabolic modules that regulate macrophage polarization. Immunity. (2015) 42:419-30. doi: 10.1016/j.immuni.2015.02.005

114. Haschemi A, Kosma P, Gille L, Evans CR, Burant CF, Starkl P, et al. The sedoheptulose kinase CARKL directs macrophage polarization through control of glucose metabolism. Cell Metab. (2012) 15:81326. doi: 10.1016/j.cmet.2012.04.023

115. Huang SC, Smith AM, Everts B, Colonna M, Pearce EL, Schilling JD, et al. Metabolic reprogramming mediated by the mTORC2-IRF4 signaling axis is essential for macrophage alternative activation. Immunity. (2016) 45:817-30. doi: 10.1016/j.immuni.2016.09.016

116. Tan Z, Xie N, Cui H, Moellering DR, Abraham E, Thannickal VJ, et al. Pyruvate dehydrogenase kinase 1 participates in macrophage polarization via regulating glucose metabolism. J Immunol. (2015) 194:60829. doi: 10.4049/jimmunol.1402469

117. Wang F, Zhang S, Vuckovic I, Jeon R, Lerman A, Folmes CD, et al. Glycolytic stimulation is not a requirement for M2 macrophage differentiation. Cell Metab. (2018) 28:463-75 e4. doi: 10.1016/j.cmet.2018.08.012

118. Huang SC, Everts B, Ivanova Y, O’Sullivan D, Nascimento M, Smith AM, et al. Cell-intrinsic lysosomal lipolysis is essential for alternative activation of macrophages. Nat Immunol. (2014) 15:846-55. doi: 10.1038/ni.2956

119. Vats D, Mukundan L, Odegaard JI, Zhang L, Smith KL, Morel CR, et al. Oxidative metabolism and PGC- $1 \beta$ attenuate macrophage-mediated inflammation. Cell Metab. (2006) 4:13-24. doi: 10.1016/j.cmet.2006.08.006

120. Johnson AR, Qin Y, Cozzo AJ, Freemerman AJ, Huang MJ, Zhao L, et al. Metabolic reprogramming through fatty acid transport protein 1 (FATP1) regulates macrophage inflammatory potential and adipose inflammation. Mol Metab. (2016) 5:506-26. doi: 10.1016/j.molmet.2016.04.005

121. Furuhashi M, Fucho R, Gorgun CZ, Tuncman G, Cao H, Hotamisligil GS. Adipocyte/macrophage fatty acid-binding proteins contribute to metabolic deterioration through actions in both macrophages and adipocytes in mice. J Clin Invest. (2008) 118:2640-50. doi: 10.1172/JCI34750

122. Malandrino MI, Fucho R, Weber $M$, Calderon-Dominguez $M$, Mir JF, Valcarcel L, et al. Enhanced fatty acid oxidation in adipocytes and macrophages reduces lipid-induced triglyceride accumulation and inflammation. Am J Physiol Endocrinol Metab. (2015) 308:E756-69. doi: 10.1152/ajpendo.00362.2014

123. Madrazo JA, Kelly DP. The PPAR trio: regulators of myocardial energy metabolism in health and disease. J Mol Cell Cardiol. (2008) 44:96875. doi: 10.1016/j.yjmcc.2008.03.021 
124. Odegaard JI, Ricardo-Gonzalez RR, Goforth MH, Morel CR, Subramanian $\mathrm{V}$, Mukundan L, et al. Macrophage-specific PPAR $\gamma$ controls alternative activation and improves insulin resistance. Nature. (2007) 447:111620. doi: 10.1038 /nature 05894

125. Kang K, Reilly SM, Karabacak V, Gangl MR, Fitzgerald K, Hatano B, et al. Adipocyte-derived Th2 cytokines and myeloid PPARdelta regulate macrophage polarization and insulin sensitivity. Cell Metab. (2008) 7:48595. doi: 10.1016/j.cmet.2008.04.002

126. Venkateswaran A, Laffitte BA, Joseph SB, Mak PA, Wilpitz DC, Edwards PA, et al. Control of cellular cholesterol efflux by the nuclear oxysterol receptor LXR $\alpha$. Proc Natl Acad Sci USA. (2000) 97:12097102. doi: 10.1073 /pnas.200367697

127. Venkateswaran A, Repa JJ, Lobaccaro JM, Bronson A, Mangelsdorf DJ, Edwards PA. Human white/murine ABC8 mRNA levels are highly induced in lipid-loaded macrophages. a transcriptional role for specific oxysterols. J Biol Chem. (2000) 275:14700-7. doi: 10.1074/jbc.275. 19.14700

128. Mak PA, Laffitte BA, Desrumaux C, Joseph SB, Curtiss LK, Mangelsdorf DJ, et al. Regulated expression of the apolipoprotein E/C-I/C-IV/C-II gene cluster in murine and human macrophages. a critical role for nuclear liver X receptors $\alpha$ and $\beta$. J Biol Chem. (2002) 277:319008. doi: 10.1074/jbc.M202993200

129. Laffitte BA, Repa JJ, Joseph SB, Wilpitz DC, Kast HR, Mangelsdorf DJ, et al. LXRs control lipid-inducible expression of the apolipoprotein E gene in macrophages and adipocytes. Proc Natl Acad Sci USA. (2001) 98:50712. doi: $10.1073 /$ pnas. 98.2 .507

130. Scott CL, T'Jonck W, Martens L, Todorov H, Sichien D, Soen B, et al. The transcription factor ZEB2 is required to maintain the tissue-specific identities of macrophages. Immunity. (2018) 49:312-25 e5. doi: 10.1016/j.immuni.2018.07.004

131. Joseph SB, Castrillo A, Laffitte BA, Mangelsdorf DJ, Tontonoz P. Reciprocal regulation of inflammation and lipid metabolism by liver $\mathrm{X}$ receptors. Nat Med. (2003) 9:213-9. doi: 10.1038/nm820

132. Marathe C, Bradley MN, Hong C, Lopez F, Ruiz de Galarreta CM, Tontonoz P, et al. The arginase II gene is an anti-inflammatory target of liver X receptor in macrophages. J Biol Chem. (2006) 281:32197206. doi: 10.1074/jbc.M605237200

133. Im SS, Yousef L, Blaschitz C, Liu JZ, Edwards RA, Young SG, et al. Linking lipid metabolism to the innate immune response in macrophages through sterol regulatory element binding protein-1a. Cell Metab. (2011) 13:5409. doi: 10.1016/j.cmet.2011.04.001

134. Oishi Y, Spann NJ, Link VM, Muse ED, Strid T, Edillor C, et al. SREBP1 contributes to resolution of pro-inflammatory TLR4 signaling by reprogramming fatty acid metabolism. Cell Metab. (2017) 25:41227. doi: 10.1016/j.cmet.2016.11.009

135. van der Krieken SE, Popeijus HE, Mensink RP, Plat J. CCAAT/enhancer binding protein $\beta$ in relation to ER stress, inflammation, and metabolic disturbances. Biomed Res Int. (2015) 2015:324815. doi: 10.1155/2015/ 324815

136. Ruffell D, Mourkioti F, Gambardella A, Kirstetter P, Lopez RG, Rosenthal $\mathrm{N}$, et al. A CREB-C/EBP $\beta$ cascade induces M2 macrophage-specific gene expression and promotes muscle injury repair. Proc Natl Acad Sci USA. (2009) 106:17475-80. doi: 10.1073/pnas.0908641106

137. Lee B, Qiao L, Lu M, Yoo HS, Cheung W, Mak R, et al. C/EBP $\alpha$ regulates macrophage activation and systemic metabolism. Am J Physiol Endocrinol Metab. (2014) 306:E1144-54. doi: 10.1152/ajpendo.00002.2014

138. Rahman SM, Janssen RC, Choudhury M, Baquero KC, Aikens RM, de la Houssaye BA, et al. CCAAT/enhancer-binding protein $\beta \quad(\mathrm{C} / \mathrm{EBP} \beta)$ expression regulates dietary-induced inflammation in macrophages and adipose tissue in mice. J Biol Chem. (2012) 287:34349-60. doi: 10.1074/jbc.M112.410613

139. Nomura M, Liu J, Rovira, II, Gonzalez-Hurtado E, Lee J, Wolfgang MJ, et al. Fatty acid oxidation in macrophage polarization. Nat Immunol. (2016) 17:216-7. doi: 10.1038/ni.3366

140. Moon JS, Nakahira K, Chung KP, DeNicola GM, Koo MJ, Pabon $\mathrm{MA}$, et al. NOX4-dependent fatty acid oxidation promotes NLRP3 inflammasome activation in macrophages. Nat Med. (2016) 22:100212. doi: $10.1038 / \mathrm{nm} .4153$
141. Hall CJ, Boyle RH, Astin JW, Flores MV, Oehlers SH, Sanderson LE, et al. Immunoresponsive gene 1 augments bactericidal activity of macrophagelineage cells by regulating $\beta$-oxidation-dependent mitochondrial ROS production. Cell Metab. (2013) 18:265-78. doi: 10.1016/j.cmet.2013.06.018

142. Wen H, Gris D, Lei Y, Jha S, Zhang L, Huang MT, et al. Fatty acid-induced NLRP3-ASC inflammasome activation interferes with insulin signaling. Nat Immunol. (2011) 12:408-15. doi: 10.1038/ni.2022

143. Weber KJ, Sauer M, He L, Tycksen E, Kalugotla G, Razani B, et al. $\operatorname{PPAR} \gamma$ deficiency suppresses the release of IL- $1 \beta$ and IL- $1 \alpha$ in macrophages via a type 1 IFN-dependent mechanism. J Immunol. (2018) 201:205469. doi: 10.4049/jimmunol.1800224

144. Infantino V, Convertini P, Cucci L, Panaro MA, Di Noia MA, Calvello R, et al. The mitochondrial citrate carrier: a new player in inflammation. Biochem J. (2011) 438:433-6. doi: 10.1042/BJ20111275

145. Infantino V, Iacobazzi V, Palmieri F, Menga A. ATP-citrate lyase is essential for macrophage inflammatory response. Biochem Biophys Res Commun. (2013) 440:105-11. doi: 10.1016/j.bbrc.2013.09.037

146. Min BK, Park S, Kang HJ, Kim DW, Ham HJ, Ha CM, et al. Pyruvate dehydrogenase kinase is a metabolic checkpoint for polarization of macrophages to the M1 phenotype. Front Immunol. (2019) 10:944. doi: 10.3389/fimmu.2019.00944

147. Meiser J, Kramer L, Sapcariu SC, Battello N, Ghelfi J, D'Herouel AF, et al. Pro-inflammatory macrophages sustain pyruvate oxidation through pyruvate dehydrogenase for the synthesis of itaconate and to enable cytokine expression. J Biol Chem. (2016) 291:3932-46. doi: 10.1074/jbc.M115.676817

148. Cordes T, Wallace M, Michelucci A, Divakaruni AS, Sapcariu SC, Sousa $\mathrm{C}$, et al. Immunoresponsive gene 1 and itaconate inhibit succinate dehydrogenase to modulate intracellular succinate levels. J Biol Chem. (2016) 291:14274-84. doi: 10.1074/jbc.M115.685792

149. Lampropoulou V, Sergushichev A, Bambouskova M, Nair S, Vincent EE, Loginicheva E, et al. Itaconate links inhibition of succinate dehydrogenase with macrophage metabolic remodeling and regulation of inflammation. Cell Metab. (2016) 24:158-66. doi: 10.1016/j.cmet.2016.06.004

150. Mills EL, Kelly B, Logan A, Costa ASH, Varma M, Bryant CE, et al. Succinate dehydrogenase supports metabolic repurposing of mitochondria to drive inflammatory macrophages. Cell. (2016) 167:457-70 e13. doi: 10.1016/j.cell.2016.08.064

151. Littlewood-Evans A, Sarret S, Apfel V, Loesle P, Dawson J, Zhang J, et al. GPR91 senses extracellular succinate released from inflammatory macrophages and exacerbates rheumatoid arthritis. J Exp Med. (2016) 213:1655-62. doi: 10.1084/jem.20160061

152. Keiran N, Ceperuelo-Mallafre V, Calvo E, Hernandez-Alvarez MI, Ejarque M, Nunez-Roa C, et al. SUCNR1 controls an anti-inflammatory program in macrophages to regulate the metabolic response to obesity. Nat Immunol. (2019) 20:581-92. doi: 10.1038/s41590-019-0372-7

153. Artyomov MN, Sergushichev A, Schilling JD. Integrating immunometabolism and macrophage diversity. Semin Immunol. (2016) 28:417-24. doi: 10.1016/j.smim.2016.10.004

154. He L, Weber KJ, Schilling JD. Glutamine modulates macrophage lipotoxicity. Nutrients. (2016) 8:215. doi: 10.3390/nu8040215

155. Palmieri EM, Menga A, Martin-Perez R, Quinto A, Riera-Domingo C, De Tullio G, et al. Pharmacologic or genetic targeting of glutamine synthetase skews macrophages toward an M1-like phenotype and inhibits tumor metastasis. Cell Rep. (2017) 20:1654-66. doi: 10.1016/j.celrep.2017.07.054

156. Liu PS, Wang H, Li X, Chao T, Teav T, Christen S, et al. $\alpha$-ketoglutarate orchestrates macrophage activation through metabolic and epigenetic reprogramming. Nat Immunol. (2017) 18:985-94. doi: 10.1038/ni.3796

157. Ren W, Xia Y, Chen S, Wu G, Bazer FW, Zhou B, et al. Glutamine metabolism in macrophages: a novel target for obesity/type 2 diabetes. Adv Nutr. (2019) 10:321-30. doi: 10.1093/advances/nmy084

158. Yang Z, Ming XF. Functions of arginase isoforms in macrophage inflammatory responses: impact on cardiovascular diseases and metabolic disorders. Front Immunol. (2014) 5:533. doi: 10.3389/fimmu.2014.00533

159. Keuper M. On the role of macrophages in the control of adipocyte energy metabolism. Endocr Connect. (2019) 1: EC-19-0016.R1. doi: 10.1530/EC-19-0016

160. Valdearcos M, Douglass JD, Robblee MM, Dorfman MD, Stifler DR, Bennett ML, et al. Microglial inflammatory signaling orchestrates the 
hypothalamic immune response to dietary excess and mediates obesity susceptibility. Cell Metab. (2017) 26:185-97 e3. doi: 10.1016/j.cmet.2017. 05.015

161. Wolf Y, Boura-Halfon S, Cortese N, Haimon Z, Sar Shalom H, Kuperman $\mathrm{Y}$, et al. Brown-adipose-tissue macrophages control tissue innervation and homeostatic energy expenditure. Nat Immunol. (2017) 18:66574. doi: $10.1038 /$ ni. 3746

162. Henao-Mejia J, Elinav E, Jin C, Hao L, Mehal WZ, Strowig T, et al. Inflammasome-mediated dysbiosis regulates progression of NAFLD and obesity. Nature. (2012) 482:179-85. doi: 10.1038/ nature 10809

163. Montgomery MK, Hallahan NL, Brown SH, Liu M, Mitchell TW, Cooney GJ, et al. Mouse strain-dependent variation in obesity and glucose homeostasis in response to high-fat feeding. Diabetologia. (2013) 56:112939. doi: 10.1007/s00125-013-2846-8

Conflict of Interest: The authors declare that the research was conducted in the absence of any commercial or financial relationships that could be construed as a potential conflict of interest.

Copyright (c) 2020 Daemen and Schilling. This is an open-access article distributed under the terms of the Creative Commons Attribution License (CC BY). The use, distribution or reproduction in other forums is permitted, provided the original author(s) and the copyright owner(s) are credited and that the original publication in this journal is cited, in accordance with accepted academic practice. No use, distribution or reproduction is permitted which does not comply with these terms. 